Considerations for Emerging Markets for Energy Savings Certificates

Barry Friedman and Lori Bird National Renewable Energy Laboratory

Galen Barbose

Lawrence Berkeley National Laboratory
Technical Report NREL/TP-670-44072

October 2008

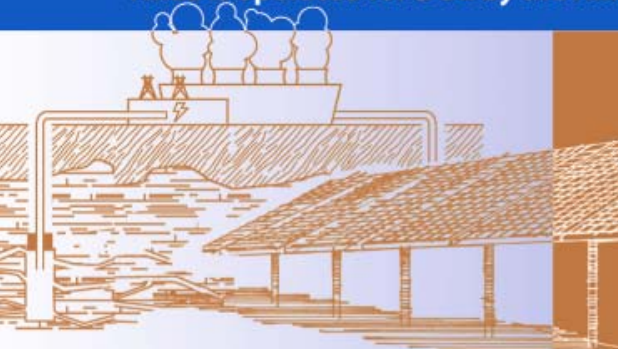




\section{Considerations for} Emerging Markets for Energy Savings Certificates

Barry Friedman and Lori Bird National Renewable Energy Laboratory

\section{Galen Barbose}

\section{Lawrence Berkeley National Laboratory}

Prepared under Task No.SAO7.8730
Technical Report NREL/TP-670-44072

October 2008

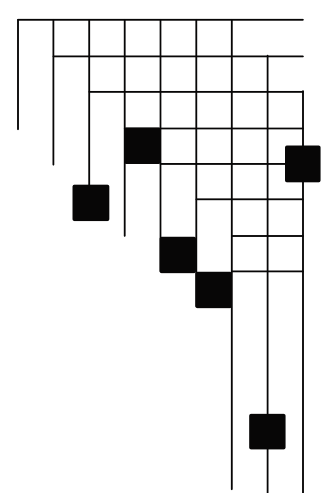




\section{NOTICE}

This report was prepared as an account of work sponsored by an agency of the United States government. Neither the United States government nor any agency thereof, nor any of their employees, makes any warranty, express or implied, or assumes any legal liability or responsibility for the accuracy, completeness, or usefulness of any information, apparatus, product, or process disclosed, or represents that its use would not infringe privately owned rights. Reference herein to any specific commercial product, process, or service by trade name, trademark, manufacturer, or otherwise does not necessarily constitute or imply its endorsement, recommendation, or favoring by the United States government or any agency thereof. The views and opinions of authors expressed herein do not necessarily state or reflect those of the United States government or any agency thereof.

Available electronically at http://www.osti.gov/bridge

Available for a processing fee to U.S. Department of Energy and its contractors, in paper, from:

U.S. Department of Energy

Office of Scientific and Technical Information

P.O. Box 62

Oak Ridge, TN 37831-0062

phone: 865.576 .8401

fax: 865.576 .5728

email: mailto:reports@adonis.osti.gov

Available for sale to the public, in paper, from:

U.S. Department of Commerce

National Technical Information Service

5285 Port Royal Road

Springfield, VA 22161

phone: 800.553 .6847

fax: 703.605.6900

email: orders@ntis.fedworld.gov

online ordering: http://www.ntis.gov/ordering.htm 


\section{Table of Contents}

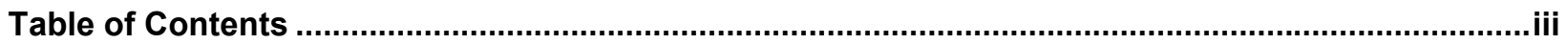

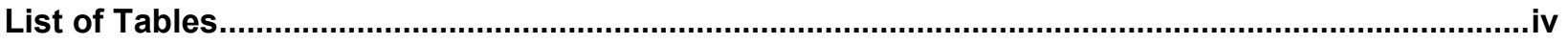

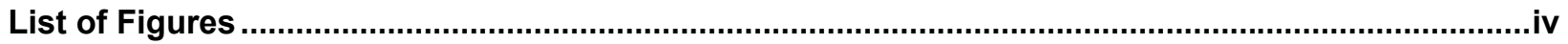

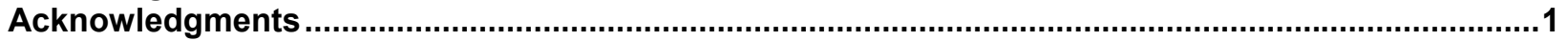

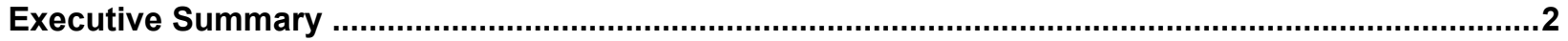

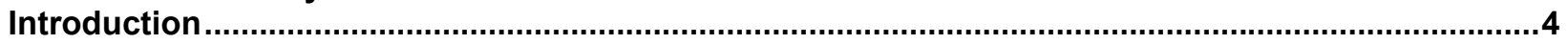

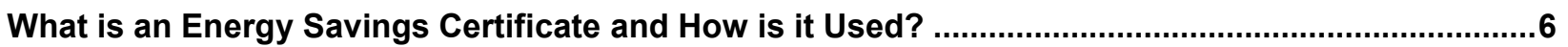

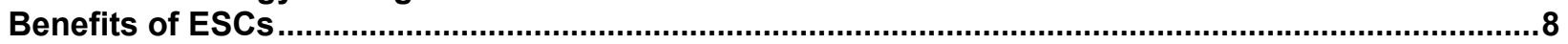

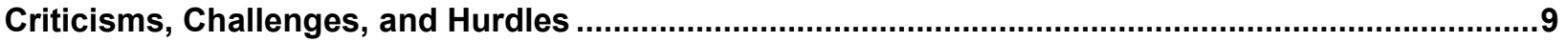

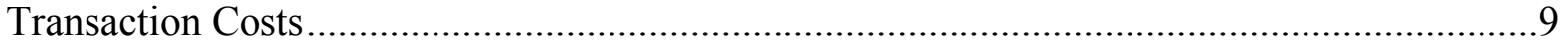

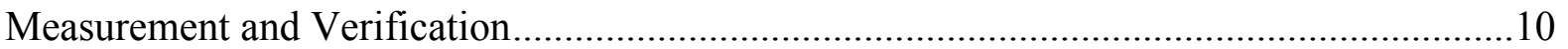

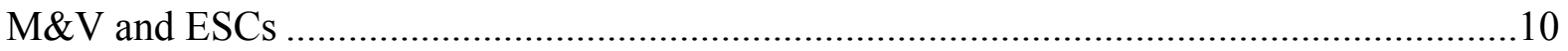

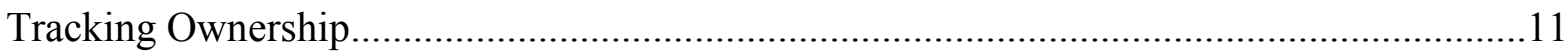

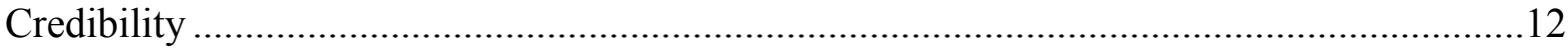

Trading as a Potential Weakening Force in EEPS Design .................................................13

Challenges Unique to a National EEPS .......................................................................... 14

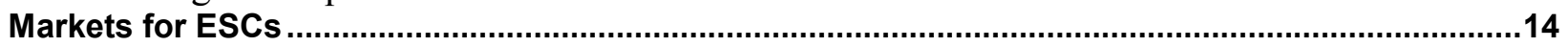

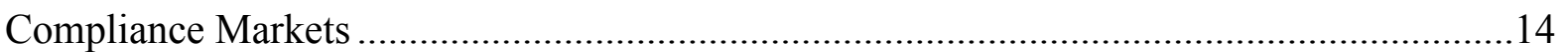

ESC Interaction with RECs and RPS Markets ............................................................... 18

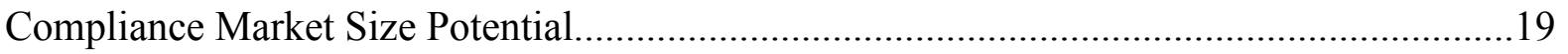

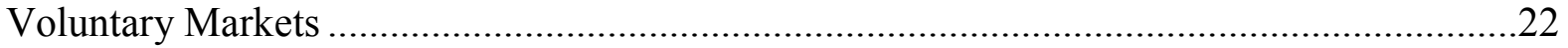

New York Voluntary ESC Pilot Program ....................................................................23

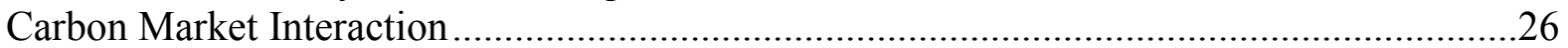

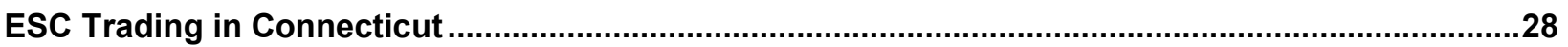

Context for the Connecticut ESC Program .......................................................................29

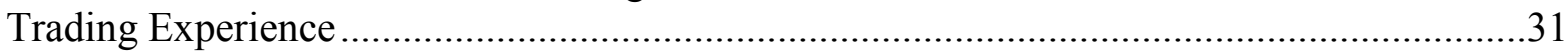

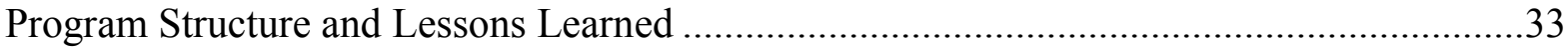

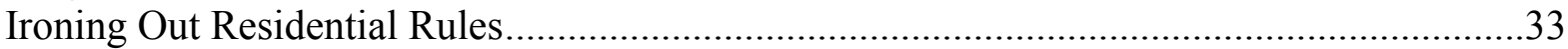

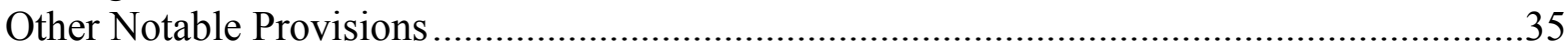

Key Structural Elements of ESCs Programs

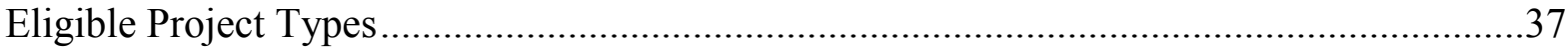

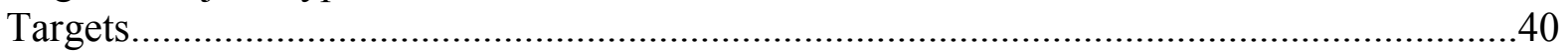

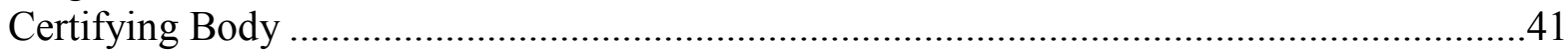

Additionality, Free Ridership, and Cream Skimming .......................................................42

Trading Rules: Obligated Entities and Parties Eligible to Trade ........................................42

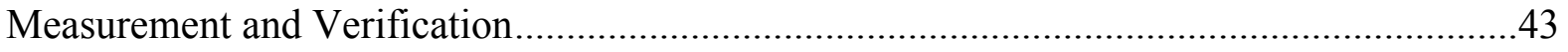

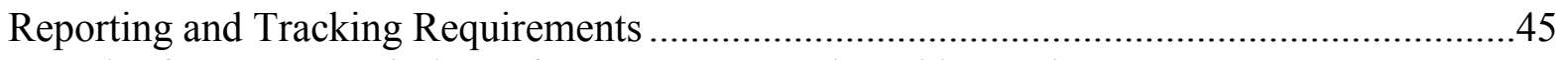

Length of Issuance Period, Up-front Issuance, and Banking Rules ...................................47

Alternative Compliance Payments (ACPs) ........................................................................48

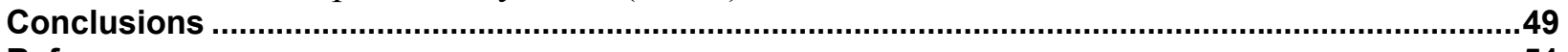

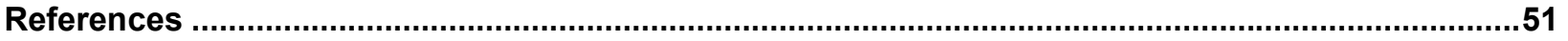




\section{List of Tables}

Table 1. States with Electricity EEPS Stand-Alone Policies ...........................................................16

Table 2. States with Electricity Energy Savings Integrated within RPS .......................................17

Table 3. Potential ESC Compliance Market in States with Existing Long-Term Energy

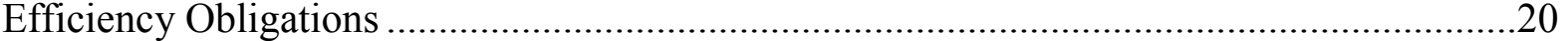

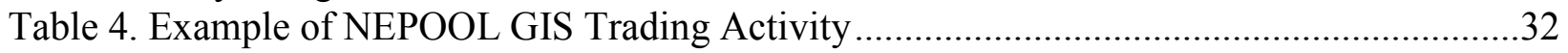

Table 5. C\&LM Class III Credits Available from CL\&P and UI (MWh) ....................................32

Table 6. ESC Schemes and Eligible Project Types ......................................................................39

Table 7. Targets for European and Australian Trading Schemes ..................................................41

\section{List of Figures}

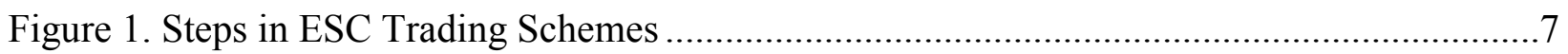

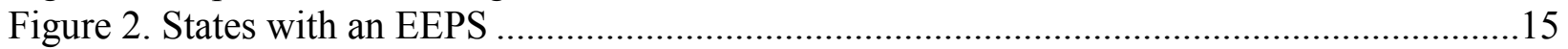

Figure 3. The Flow of ESCs in the Connecticut Compliance Trading Scheme ……….................30 


\section{Acknowledgments}

This work was funded by the U.S. Department of Energy (DOE) Office of Energy Efficiency and Renewable Energy (EERE). The authors wish to thank Linda Silverman, John Atcheson as well as the Office of Planning, Budget, and Analysis (PBA) and the Weatherization and Intergovernmental Program (WIP) for their support of this work.

We also wish to thank the following individuals for their thoughtful review comments: Ron Benioff and Elizabeth Brown of NREL, Ed Vine of Lawrence Berkeley National Laboratory, Paolo Bertoldi of the European Commission, David Goldberg of the Connecticut Clean Energy Fund, Alfred Mascola and Pat McDonnell of United Illuminated, Steve Bruno of Connecticut Power \& Light, Kelly Bennett of Sterling Planet, Steve Nadel and Laura Furrey of American Council for an Energy-Efficient Economy, Matthew Brown of InterEnergy Solutions, Joe Loper of the Alliance to Save Energy, and Joel N. Gordes of Environmental Energy Solutions. And, finally, we offer many thanks to Michelle Kubik of NREL for her editorial support. 


\section{Executive Summary}

Early experiences with energy savings certificates (ESCs) have revealed both their merit and the challenges associated with them. In the United States, there has been little activity to date, so any lessons must be drawn from experiences in Italy, the United Kingdom (UK), France, and elsewhere. The staying power of European examples, particularly in Italy, demonstrates that ESCs can help initiate more efficiency projects. Although a robust market for renewable energy certificates (RECs) has emerged in both the voluntary and policy compliance contexts in the United States, ESCs have yet to gain significant traction.

However, because of the large number of energy efficiency portfolio standards (EEPS) that have been adopted in recent years in the United States, there is now an increased opportunity for ESC trading to emerge. A sharply increased public awareness of the role of energy efficiency (EE) in climate change policy also presents a renewed opportunity for ESCs, a concept that has been promoted by energy efficiency advocates for some time. But given unique challenges to date in the U.S. voluntary market, ESCs may have more of a role to play in facilitating EEPS compliance, at least in the short term.

It is unclear at this early stage whether a voluntary market for ESCs will develop as it has for RECs. The emergence of a credible, independent national certifying body and consistent set of protocols, as well as the success of early examples, most likely will influence those prospects. REC markets have shown that there is market potential for tradable commodities that represent a public good and an opportunity for consumers to "vote with their wallets." But a voluntary ESC market must cross an additional hurdle that RECs have not faced: public acceptance of the notion of taking action that eventually results in saving money, and then turning around and selling the proof of that savings for yet more income. Is this an unwarranted double benefit?

This report looks at the opportunity presented by ESCs, the unique challenges they bring, a comparison with RECs that can inform expectations about ESC market development, and the solutions and best practices early ESC market experience have demonstrated. It also examines whether there are real market barriers that have kept ESCs from being adopted and what structural features are necessary to develop effective trading programs.

The most significant challenge ESCs face is the need to balance the development of credible standards with the likelihood that regimes will be developed on very tight budgets. Because establishing high standards for certain aspects, such as measurement and verification $(\mathrm{M} \& \mathrm{~V})$, can add to transaction costs, these two values must be carefully balanced.

In this regard, ESCs can benefit from existing markets and mechanisms to reduce costs. They can benefit from the traction that RECs have gained in the marketplace, along with the existing infrastructure developed for REC markets, such as tracking systems. These systems could be modified relatively easily to accommodate ESC trading. ESCs also can 
benefit from existing $M \& V$ protocols and other data acquired through long-standing efficiency and public benefit programs.

The key challenges and design considerations for ESCs are as follows:

- Balancing the need for market integrity with the need to carefully manage transaction costs, including those related to tracking and preventing doublecounting. Maintaining transparency in transactional information and rules implementation.

- Ensuring real, measurable, verified savings that take into account the following issues:

- Establishment of a central, credible certifying body.

- Additionality tests that ensure a measure is beyond business as usual (BAU), effectively handling related issues of free ridership and cream skimming.

- Clear, uniform, rigorous measurement and verification $(\mathrm{M} \& \mathrm{~V})$ based on established protocols, across disparate technologies and circumstances.

- Length of period for which ESCs are issued and up-front ESC issuance where appropriate.

- Alternative compliance payments.

- Close scrutiny of double-counting through an established system of tracking and/or certificate attestation process. ${ }^{1}$

- Developing rules for banking ESCs that provide for flexibility and increase the value of energy savings but do not overly weaken policies.

- Communicating a value proposition of separated environmental and social attributes.

- Providing for ESC ownership in a manner that is fair to both facilities investing in energy savings and organizations providing energy saving services. For example, the installer of high efficiency equipment could give a discount to end users paying for the installation, in exchange for ESC ownership.

- Providing for third-party trading, opening the market beyond obligated entities.

- Maximizing the ability to piggy-back on to existing electronic REC tracking systems.

- Integrating ESCs with carbon offset and REC markets in a manner that does not muddy perceptions of both.

- Providing early planning for inter-market, interregional, and international trading.

If ESCs are traded under rules that are developed with a solid, well-planned foundation and the support of authorized, objective third-party certifying bodies, they can establish themselves as an accepted consumer product and have a beneficial effect on the broader voluntary demand for energy efficiency. The obstacles remain formidable and it is too soon to say whether this potential will find fruition. The opportunity for ESCs' use in the compliance context is the more promising, not only as an end in itself but as a means to reap lessons learned, gain public and stakeholder acceptance, and pave the way for the voluntary side.

\footnotetext{
${ }^{1}$ Attestations are documents verifying contract paths for a certificate, its chain of ownership.
} 


\section{Introduction}

For a number of years, the concept of creating, and even trading, verified fixed units of energy savings, through energy efficiency or load management, has been proffered as a vehicle to increase the amount of savings implemented in the United States. However, the country has only started to adopt energy savings certificates (ESCs), sometimes referred to as "white tags," in the past two years. The energy savings analog to renewable energy certificates (RECs), ESCs have the potential to bring the same market-based flexibility to energy efficiency that RECs have brought to renewable energy.

Yet that opportunity remains largely untapped, even though energy efficiency has been a priority of regulators and conservationists for decades. Public and stakeholder understanding of, or belief in, ESCs is likely low, which is similar to early experiences in the REC market. This is partly fed by a somewhat persistent perception that energy efficiency measures are unreliable, unpredictable, or unenforceable (Hamrin et al. 2007).

Energy efficiency has been called "the first fuel" to signify that saving energy and using electricity more efficiently are often considered foundational steps in a multipronged environmental strategy. To paraphrase one oft-repeated catchphrase, "the cleanest MWh of electricity is the one that is never used." Many policy makers consider efficiency to be the most cost-effective solution to address rapidly increasing demands on congested transmission systems (Vine 2008). Following rolling brownouts during the California energy crisis of 2000-01, several Western state utility commissions approved increased spending for efficiency (Geller 2006).

Today, as energy efficiency is gaining a more popular foothold as a critical solution to increasing energy prices, energy security, and global climate change, regulators and market participants are giving more attention to ways to encourage its adoption. Several studies have identified a critical role for energy efficiency in reducing global carbon emissions. In their 2004 identification of 15 "stabilization wedges" to collectively mitigate climate change, Princeton analysts Steven Pacala and Robert Socolow identified four energy efficiency and conservation wedges, including the potential for the buildings sector to cut its carbon emissions by one-fourth, by $2050 .^{2}$ In a hearing before the Joint Economic Committee of Congress on July 30, 2008, in which Senator Charles Schumer (D-NY) suggested ESC trading to the committee, Jonathan Koomey of the Lawrence Berkeley National Laboratory (LBNL) testified that energy efficiency is the "fastest, cheapest, and cleanest" way to address energy security and climate risks (Koomey 2008).

Still in an early stage of development, ESC markets can play a role in fostering energy efficiency, but not before the principles of a well-designed ESC trading platform are understood. REC markets provide some useful lessons but not a perfect blueprint. It is too soon to know whether momentum will be generated for ESCs analogous to, for example, the critical mass that has been created for recycling and recycled products in the United States in the past 15 years - after a slow start of low consumer awareness and interest.

\footnotetext{
${ }^{2}$ Each wedge would contribute one gigaton of carbon reduction (GtC/y) by 2054.
} 
It is unclear at this early stage whether a voluntary market for ESCs will develop as it has for RECs. To no small degree, experience with REC markets has shown that traction in voluntary markets can be a function of the success of compliance markets. Although there can be no definitive answer to the "chicken-and-egg" causative question of markets versus mandates, the early compliance markets for ESCs likely will similarly drive voluntary interest more than the other way around. This is because compared with RECs, ESCs are perhaps even more tenuous in their ability to be understood and accepted as a credible instrument demonstrating real, additional environmental benefit. Unlike RECs, ESCs cannot rely on readily verified metered data to demonstrate measurable results, but depend instead on comparatively complex measurement and verification protocols, which can vary from one compliance regime to another.

To date, four U.S. states, three European countries, and New South Wales have incorporated ESCs into policies that establish energy efficiency targets, often referred to as energy efficiency portfolio standards (EEPS). India's National Action Plan on Climate Change contemplates a future national market for ESCs in that country. ${ }^{3}$ In addition, the European Commission is examining whether it should propose an ESC trading scheme across the EU. ${ }^{4}$ In the United States, only Connecticut is actively trading ESCs.

This analysis explores the benefits of ESCs and the obstacles and challenges associated with their adoption. We review three major potential ESC markets: compliance, voluntary, and carbon. The analysis begins with a review of EEPS policies in the United States as the context for future compliance markets, examining ESCs' potential market size in that context. We review the limited voluntary activity in the United States for ESCs to date and their potential interaction with carbon offset markets.

The analysis explores the structure of how ESC trading can work in the United States using the Connecticut features as an example, and takes a closer look at each design feature using European examples. These components include rules for the types of projects for which ESCs can be issued; the types of parties who can buy and sell them; rules for issuing ESCs, tracking their ownership, and retiring them; rules for who can verify and certify that a given ESC is what it purports to be; and the monitoring and verification $(\mathrm{M} \& \mathrm{~V})$ protocols to be used for that verification. ESCs in other states and in the voluntary market are likely keeping a close eye on how these various elements are treated in existing ESC schemes, examining how each translates into the desired result: increased cost-effective energy savings activities.

\footnotetext{
${ }^{3}$ See http://www.pewclimate.org/international/country-policies/india-climate-plan-summary/06-2008.

${ }^{4}$ Directive 2006/32/EC of the European Parliament and of the Council of 5 April 2006 on energy end-use efficiency and energy services and repealing Council Directive 93/76/EEC (accessed from http://eurlex.europa.eu)
} 


\section{What is an Energy Savings Certificate and How is it Used?}

Similar to RECs, ESCs have various names: white tags, energy efficiency certificates or credits, and others. But regardless of the moniker, an ESC is simply an instrument representing a unit of energy savings that has been measured and verified. ESCs allow parties to trade the attributes of energy savings: The ESC represents an ownership right to the intangible bundle of societal and environmental benefits created by the fixed quantity of energy savings with which the ESC is associated.

An ESC can be represented in units of electricity savings, such as 1 megawatt hour (MWh); or in common energy units that enable direct comparisons between gas efficiency and electricity savings, such as British thermal units (BTUs) or tons of oil equivalent (TOEs). ${ }^{5}$ ESCs can be designed to incorporate estimated savings (typically discounted) over the expected lifetime of the efficiency measure or to represent energy savings accrued annually - both approaches have been used. Assigning $1 \mathrm{MWh}$ to an ESC likely simplifies its use, both because it makes an ESC more easily comparable to a REC (Bertoldi and Huld 2004) and because most EEPS policies in the United States focus on electricity savings.

Integral to their design, ESCs are a device that can be used to buy and sell these benefits as a separate commodity, either bilaterally or at auction, with the bundle of benefits belonging to each successive owner. The ESC is finally credited to the owner of the ESC when it is retired, and that owner may make the associated claims concerning the energy savings. Similar to RECs, ESCs are intended to be retired only once, for one purpose only. Generally, an authorized body is required to ensure credibility in carrying out the various identified stages and mechanisms required to establish effective trading schemes for ESCs. Figure 1 presents the various stages involved in the creation of ESCs.

\footnotetext{
${ }^{5}$ One TWh is equal to one million MWh. In part, the unit is a function of the aim of an ESC scheme: If the aim is improved security of supply, the target may be better defined in primary savings units to suit the policy aim; if the aim is reliability of electric supply, it may be better defined in kilowatt hours ( $\mathrm{kWh}$ ) saved (Bertoldi 2005).
} 


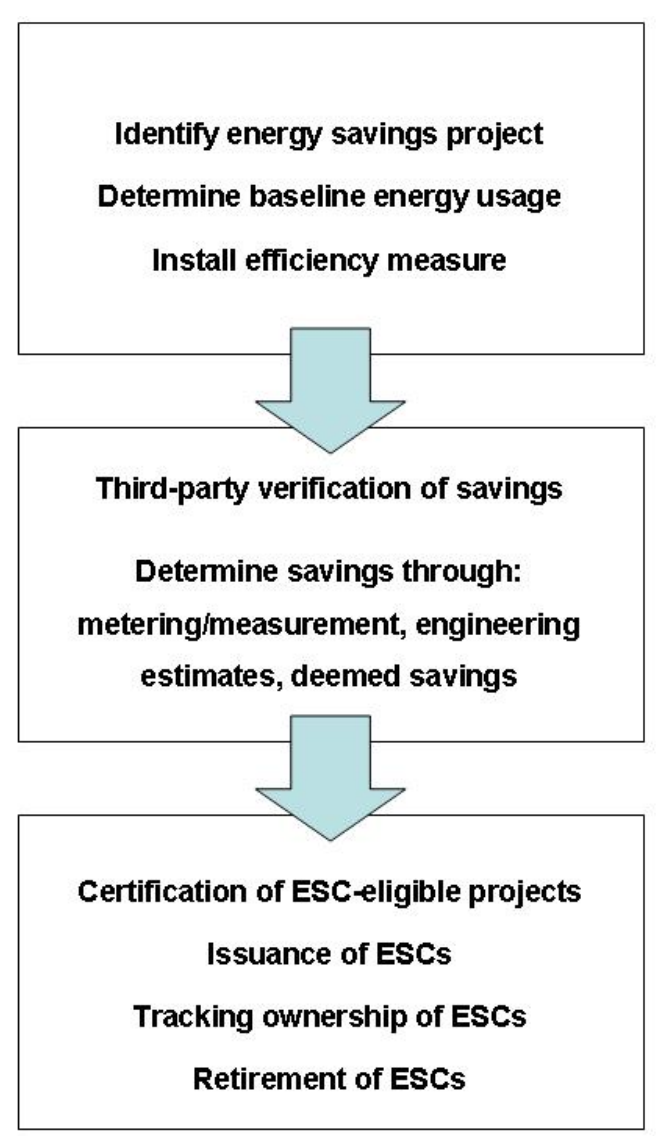

Figure 1. Steps in ESC trading schemes

ESCs have potential benefits for both voluntary and compliance markets, so that the owner who retires an ESC may do so for private purposes, such as reducing a carbon footprint, or to comply with a legal obligation, such as an EEPS. In some cases, an ESC may be used as a tool to demonstrate a reduction in carbon emissions. In addition to its function as a commodity conveying a property right, an ESC also can be an accounting tool, used to demonstrate energy efficiency implementation, or eligibility for certain tax incentives or other public subsidies associated with implementing energy efficiency or load reduction (Bertoldi et al. 2005).

In compliance markets making use of ESCs, what typically determines whether trading is allowed is the size of the market, the number of actors involved (larger markets with more players have more of a reason to encourage trading), and the role that utilities would like to play (in-house energy efficiency or outsourcing the expertise). For example in France, EDF and Gas de France, the two utilities with the largest targets, tend to implement project by themselves to position the companies as energy service providers, while in Italy the majority of ESCs are delivered to ESCOs (Bertoldi 2008). ${ }^{6}$

\footnotetext{
${ }^{6}$ Personal communication, Paolo Bertoldi, October 14, 2008.
} 


\section{Benefits of ESCs}

In conjunction with - or as an alternative to - other tools used to implement energy efficiency programs, ESCs offer unique advantages and disadvantages. As a tradable commodity, the main benefit of ESCs that has been espoused is their potential to free market forces to drive capital and capabilities to energy savings opportunities.

ESCs can enable energy efficiency to be acquired more cost-effectively. For example, by opening up trading to third parties, ESCs could increase participation by private energy service companies (ESCOs) in state EEPS compliance markets - a potential advantage because of ESCOs' unique experience and expertise with energy efficiency projects and technologies. In some cases, private actors are better able than utilities to identify and access high-value energy efficiency opportunities because of their economic interest in reaching market segments and geographic regions not easily tapped by utilities. In some cases, ESCOs' advantage may be simply a better ability to acquire energy efficiency savings at lower costs.

A similar argument could be made for other third parties in optimal positions to implement energy efficiency, such as appliance manufacturers and retailers, commercial and industrial energy end users, aggregators for residential measures, and others. Trading programs that open markets to third parties could see greater overall savings at a lower overall compliance cost, by virtue of empowering these third parties to derive value from ESCs. The competition also could result in utilities being pressured to implement their own programs more cost-effectively (Loper et al. 2008).

Because of these possibilities, ESCs could potentially increase the amount of energy savings should voluntary markets be developed. They also can do so by stretching fixed utility energy efficiency budgets further, and by expanding the size of the resource potential in states such as Washington or Massachusetts, where utilities are required to acquire "all cost-effective energy efficiency."

Most would agree that if the benefits of private markets can result in greater energy savings, then public benefits accrue. The benefits of energy savings and energy efficiency are well understood - to the extent that ESCs offer a tool to reduce payback periods and thereby encourage more energy efficiency projects to move forward, those benefits may be attributable to ESCs as well. They include reduced emissions from fossil fuelgenerated electricity that contribute to climate change, acid rain, and smog and other health effects; reduced water consumption; increased energy security; and improved ecosystems.

The decrease in electricity and fossil fuel demand brought about by efficiency also benefits the economies by delivering cost savings, which may become particularly important should U.S. climate change legislation be passed. The cost savings created by efficiency may serve to offset the higher energy prices resulting from a cap-and-trade system (ACEEE 2008). The economic benefits of energy efficiency can be particularly important to impoverished households disproportionately affected by increasing energy 
costs. Finally, improved energy efficiency can provide a competitive edge for businesses in difficult economic climates (see Bertoldi et al. 2005).

\section{Criticisms, Challenges, and Hurdles}

As attractive as the proposition seems, there is some complexity associated with developing ESCs as a tradable compliance mechanism. The challenges associated with ESCs may partly explain why they are an oft-debated but still largely unexecuted idea in the United States, particularly on the voluntary side of the ledger. They include determining which savings measures should be eligible for ESCs; managing transaction costs and scaling programs to do so; establishing clearly defined and understood standards for verifying that savings are real, credible, and accurately measured; and accurately tracking ESC ownership.

It is generally anticipated that ESCs add transaction costs to an EEPS scheme (see, for example, Vine and Hamrin 2008). To cite one example, perceived high transaction costs in the first phase of the Energy Efficient Commitment in Great Britain - about $10 \%$ of the total costs for lighting projects and about $30 \%$ for insulation projects - were found to slightly reduce levels of trading (Mundaca 2007).

\section{Transaction Costs}

Higher transaction costs associated with ESCs include those associated with the complexity of a greater number of parties involved in implementation of savings measures; the complication and cost of issuing, tracking, and certifying ESCs and related activities; and the need to pay special attention to $M \& V$ standards to ensure market integrity. Transaction costs include the direct costs of carrying out an ESC transaction, such as the cost of locating, negotiating with, and contracting with transaction counterparties (Langniss and Praetorious 2006). Finally, unlike RECs, for which generation data are obtained directly through meters and result in reliable data at low transaction costs, energy savings data for the same volume of energy as produced by renewable electricity are diffuse and would need to come from many more sources (Hamrin et al. 2007). This extensive data collection results in increased transaction costs.

The key question is the extent to which the technical hurdles associated with ESCs outweigh the benefits and, taken cumulatively, become too costly relative to the potential added revenue or compliance flexibility ESCs are intended to generate. One factor that can help tip that balance in favor of the use of ESCs is the case of larger programs with larger goals, where costs can be better spread across larger transaction volumes and the size of the program can better justify the costs (Vine 2007).

Because of the incrementally higher costs involved in programs incorporating ESCs, each element of a well-structured ESC trading program requires a delicate balance between credible results that ensure market longevity and the price tag of the mechanisms required to achieve that kind of dependability. Transaction costs can be eased by allowing projects to be aggregated and measured in the aggregate, rather than on the basis of individual projects. As programs have already discovered, M\&V for ESC programs can take 
advantage of the protocols and processes already in place through existing efficiency programs.

\section{Measurement \& Verification}

The most prominent complication with which policy makers must wrestle - and one that does not apply to RECs - is the need to establish clear uniform protocols for measuring and verifying savings $(\mathrm{M} \& \mathrm{~V})$ across disparate technologies and circumstances. $\mathrm{M} \& \mathrm{~V}$ is always an important issue for energy efficiency programs, whether or not ESCs are used. It is an added dimension to be considered in assessing whether progress REC markets have made in the United States is an indicator of the potential of ESC markets here.

Measuring the renewable energy associated with RECs is usually simply a matter of reading and reporting metered data for the process of REC issuance. Measuring and verifying savings resulting from energy efficiency improvements is considerably more complicated and can add significant costs to ESC transactions.

Fundamentally, M\&V often is not a straightforward exercise, because measuring reductions in energy consumption depends on a baseline or reference scenario, a "before" picture, which is generally a moving target that must be accurately projected. Very often, by the time energy savings are achieved, "business as usual" is no longer business as usual, because facility demand or energy use patterns have changed - typically, demand has increased.

\section{M\&V and ESCs}

Yet there is agreement among stakeholders and policy makers, reflected in the existing European ESC policies and the ESC literature, that clear, consistent M\&V protocols are crucial to the long-term success of ESC trading schemes. They agree that consistent $\mathrm{M} \& \mathrm{~V}$ is the lynchpin to ensuring that opening ESC trading to private third parties does not undermine the credibility of this new market seeking momentum. Without strong M\&V standards, savings estimates can become inflated and projects that would have been completed under business-as-usual scenarios could result in a deflation in ESC value, undermining the investments in energy efficiency intended by the EEPS (Loper et al. 2008). M\&V standards also are crucial for the task of measuring the "shelf life" of projects - how many years should ESCs be issued for a project based on how long the project is yielding real savings and the length of its payback period. In regimes where ESCs are issued up front for the life of a project, M\&V determines how much the future value of ESCs should be discounted based on risks that the shelf life might be altered during the period of expected savings, a task that is something of a hybrid between policy and engineering considerations.

Although ESCs will benefit from years of M\&V development in the broader energy efficiency markets and protocols that have been established, most notably the International Performance Measurement and Verification Protocol (IPMVP 2001), they present unique challenges. First, ESC markets may be broader than individual utility service territories or states, requiring $\mathrm{M} \& \mathrm{~V}$ standards to be harmonized across jurisdictions. Second, more robust markets for ESCs may include a broader range of 
energy efficiency measures that may be implemented in a broader range of applications, potentially requiring additional $\mathrm{M} \& \mathrm{~V}$ protocols to be developed. Third, a larger and more diverse set of entities may be involved in implementing projects, requiring some combination of training and the development of simplified M\&V options. Third-party ESC trading can complicate M\&V simply because of the need to apply and verify protocols for a diverse and numerous set of companies.

Not harmonized correctly, each of these potential areas of inconsistency could contribute to weakening faith in ESC trading in general, because of such risks as companies receiving windfall benefits without true efficiency gains. $M \& V$ for renewable energy is generally not as complex, because renewable generation data is metered and generally verified by the control area operator, who is already verifying them for transmission purposes (Hamrin 2007).

Developing a robust, liquid market for ESCs depends partly on the consistency among the methodologies and norms for establishing $\mathrm{M} \& \mathrm{~V}$ protocols and for clarity among parties as to what is actually being sold and purchased. If interstate, national, or even, eventually, international trading were to develop, consistency among protocols would prevent transactional parties from being mired unnecessarily in trying to compare apples and oranges for the same technologies. It is useful to identify the benefit of such protocol standardization at this early stage of market design and consider all best practices. For now, there is no concerted effort at such coordination, although there are many nongovernmental organizations that look across such boundaries and attempt to communicate standards.

\section{Tracking Ownership}

Another key technical hurdle to successful ESC trading programs is the requirement for tracking systems. Where trading is allowed, it is necessary to track ESCs' chain of ownership to ensure against double-counting. Accommodating the need to ensure market integrity must be accomplished at a reasonable cost, to avoid undercutting the small operating margins many efficiency projects carry. Moreover, in future trading regimes, tracking systems may need to integrate ESCs with RECs and carbon offsets to avoid confusion, duplication of efforts, and the potential for double-counting.

Tracking can be a costly element to an ESC trading scheme, particularly when it is done manually through an attestation process and not through an automated system. Along with $\mathrm{M} \& \mathrm{~V}$, the need to track ownership can create incremental costs over those of efficiency programs that do not involve ESCs, especially when administrative procedures are complex (Langniss and Praetorious 2006). There are, however, cases where this cost can be significantly mitigated by "piggy-backing" on automated generation attribute tracking systems currently used for RECs.

In Connecticut, rule-makers have attempted to do exactly that, using the New England Power Pool (NEPOOL) Generation Information System (GIS). In conjunction with market participants, APX Inc., the company that has provided the Web-based platform for most of the REC-based trading schemes, has anticipated the need for automated ESC 
tracking. Of existing United States REC tracking systems, only the North American Renewables Registry - often referred to as the "default" system because it covers all geographic regions not covered by the systems that pre-dated its launch in May 2008 was designed to track ESCs for a contemplated voluntary market, in addition to RECs.

\section{Credibility}

Ensuring that savings are "real and additional" is crucial to the success of voluntary ESC markets. Measures must be real, surplus, verifiable, and permanent - the R.S.V.P. of credible offsets. For efficiency, the primary hurdles are proving that measures are "real" and "surplus" or additional to what would otherwise have occurred. Because many efficiency measures are cost-effective over a relatively short period of time, determining standards for what measures are additional to those that would have occurred under business as usual is important.

\section{Cream Skimming}

ESC schemes must also deal with "cream skimming," participation in ESC schemes of projects with short payback periods. In their design, ESC trading programs must determine the number of years they will allow various project types to generate ESCs, based on the length of time they are expected to generate real savings and the time it will take for those savings to provide the full payback of the initial investment. Providing ESCs to projects past this estimated period can result in windfalls to project owners and higher compliance costs. Some trading programs limit the period for which ESCs may be issued for projects. To reduce the relative incentives for cream skimming, trading programs can offer ESC issuance for longer periods of time, so that those projects with longer payback periods can better compete, because they would qualify for more ESCs over the life of that payback period. If, for example, a regime only issues ESCs for five years, projects with payback periods of five years or less would gain a competitive advantage. Lengthening issuance periods in this way can increase the financial incentive for these less cost-competitive projects with longer payback periods, improving overall additionality standards. Some have argued that issuing ESCs for projects with short payback periods promotes a broader, healthier market for energy efficiency, because such projects help demonstrate the compelling economic benefits that tend to be particularly strong where payback periods are particularly short.

\section{Free Ridership}

ESC programs bringing an additional revenue stream to energy savings projects must concern themselves with "free riders," projects that were going to be implemented regardless of the additional revenue from ESCs, generally for nonenergy reasons. The preferred approach to accounting for free ridership is to adjust, or discount, the gross energy savings attributable to the program based on a "derate" factor, a percentage based on assumptions about the level of free ridership, with the resulting figure sometimes referred to as "net energy savings." These assumptions are made through studies or market experience (Vine 2008). The intent behind the use of such assumptions is to offer an approach to free ridership that is reasonable, credible, and supports the additionality threshold, while avoiding overly burdensome enforcement costs. 
Through such adjustments, regulators can prevent free ridership from causing an overestimation of the cost-effectiveness of a program when evaluating it. In a review of energy efficiency protocols in the Northeast United States, states had different rules on what adjustments were applied to gross savings to calculate net savings (Michals and Titus 2006). Other regimes employ protocols to exclude projects that are likely to be free riders from receiving ESCs, instead of applying a derate factor. In the end, policy makers must determine the right way to balance those questions in their unique situation.

\section{Trading as a Potential Weakening Force in EEPS Design}

Some argue that there are instances for which trading could create unintended consequences of weakening or narrowing EEPS policies, or making them more instead of less expensive. It could steer resources away from key energy saving policies and measures that may not qualify for ESCs, because the savings they create typically would not be attributable to individual parties obligated under the EEPS. Such policies include building codes, appliance standards, state consumer awareness and information campaigns, and tax incentives (Loper et al. 2008). Where an EEPS policy does not contemplate trading and therefore assigning ownership to ESCs from such projects, policy makers might be more inclined to credit these project types, resulting in their broader implementation.

Others argue that the introduction of market forces can result in higher rather than lower compliance costs for energy efficiency, because pricing via the market rather than through a cost basis can result in prices higher than pure cost-based pricing should deliver, with the difference increasing profit margins instead of project investment (Wolff 2008). For example, in states that have faced supply shortages in meeting RPS requirements, supply/demand imbalances have resulted in higher REC prices than what pure costs suggest they should be, because that is what the market would bear. Similarly, some argue that ESC short-supply scenarios can result in higher prices that do not necessarily yield more projects. However, energy efficiency projects do not face the same barriers as renewables, with respect to siting and transmission constraints, or the need for the same kind of long-term contracts; therefore, fewer barriers to their implementation exist. Theoretically, if markets operate without barriers, short-term overpayments should be addressed by the marketplace as a greater number of projects are implemented and drive down prices.

Another criticism of ESCs concerns local air-quality benefits, if emissions reductions are a primary goal of an EEPS policy. If entities were permitted to buy out-of-state ESCs, they might be effectively "buying" their way out of part of their obligation and undermining any local air quality benefits. However, because obligated entities have not been permitted to purchase ESCs from out-of-state projects, this has not been an issue for EEPS states thus far. Along similar lines, out-of-state ESCs would deprive a state of the reduced energy costs, reduced risk mitigation benefits, and any economic development benefits associated with energy efficiency. The same issue has been raised for RECs, which is why some RPS states have required physical delivery of renewable energy into their states to accompany compliance RECs. 


\section{Challenges Unique to a National EEPS}

It has also been argued that ESC trading could effectively reduce the stringency of a national EEPS (should one be implemented in the United States), if ESCs from so-called "business-as-usual" (BAU) projects, like those implemented for a pre-existing state EEPS, were allowed to be sold into a federal compliance market (Loper et al. 2008). In such a scenario, a utility with excess ESCs after meeting its EEPS requirement could sell those ESCs to another utility in lieu of that other utility achieving additional savings to meet its federal EEPS requirement.

In this case, trading among utilities could allow credit for more BAU programs, and thus reduce the effective stringency of the EEPS. Some contend that providing for national trading could allow obligated parties in states with stringent efficiency policies (with tougher standards for what qualifies as additional or a broader definition of the baseline of business-as-usual projects) to effectively weaken those standards by buying ESCs from states with less-aggressive baseline policies. In addition to undermining the stringent states' policy, this could provide an undesirable reward to the laggard states (Loper et al. 2008).

\section{Markets for ESCs}

There are three major markets or potential markets for ESCs: EEPS or RPS compliance, voluntary, and carbon; carbon markets also include both voluntary and compliance markets. All of these markets can benefit from consistent M\&V rules and a clear thirdparty certification body. But some issues are unique to each.

\section{Compliance Markets}

EEPS policies that create long-term targets for energy efficiency have emerged in 15 U.S. states (Figure 2, and Tables 1 and 2). ${ }^{7}$ The fact that all but three of these states have done so in the past three years demonstrates a clear trend and a renewed state interest.

EEPS policies generally apply to utilities or load-serving entities, requiring them to demonstrate a quantity of energy savings that usually increases during the life of the requirement. EEPS policies are comparable to RPS policies and, in some instances, energy efficiency targets have been incorporated into an expanded RPS. In other cases, EEPS policies are enacted with targets that are entirely separate from and independent of RPS targets; often, this occurs in states with an already well-established RPS. ${ }^{8}$

\footnotetext{
${ }^{7}$ Database of State Incentives for Renewables and Efficiency. DSIRE: Rules, Regulations, \& Policies for Energy Efficiency: http://www.dsireusa.org/summarytables/regee.cfm? \&CurrentPageID=7\&EE=1\&RE=1 Accessed July 2008. Four other states have exceptional EE standards, as follows: In Washington State, the requirement is to acquire all achievable cost-effective EE, but with no specific target; Massachusetts has the same policy. In Vermont, the state has a contract with a third-party administrator to run their energy efficiency programs, and the contract includes a performance incentive based on energy savings. Finally, Virginia has an aspirational policy, not established through legislation or regulatory order.

${ }^{8}$ Ohio has a stand-alone EEPS and also includes energy efficiency within a broader "alternative energy resource" portfolio standard.
} 


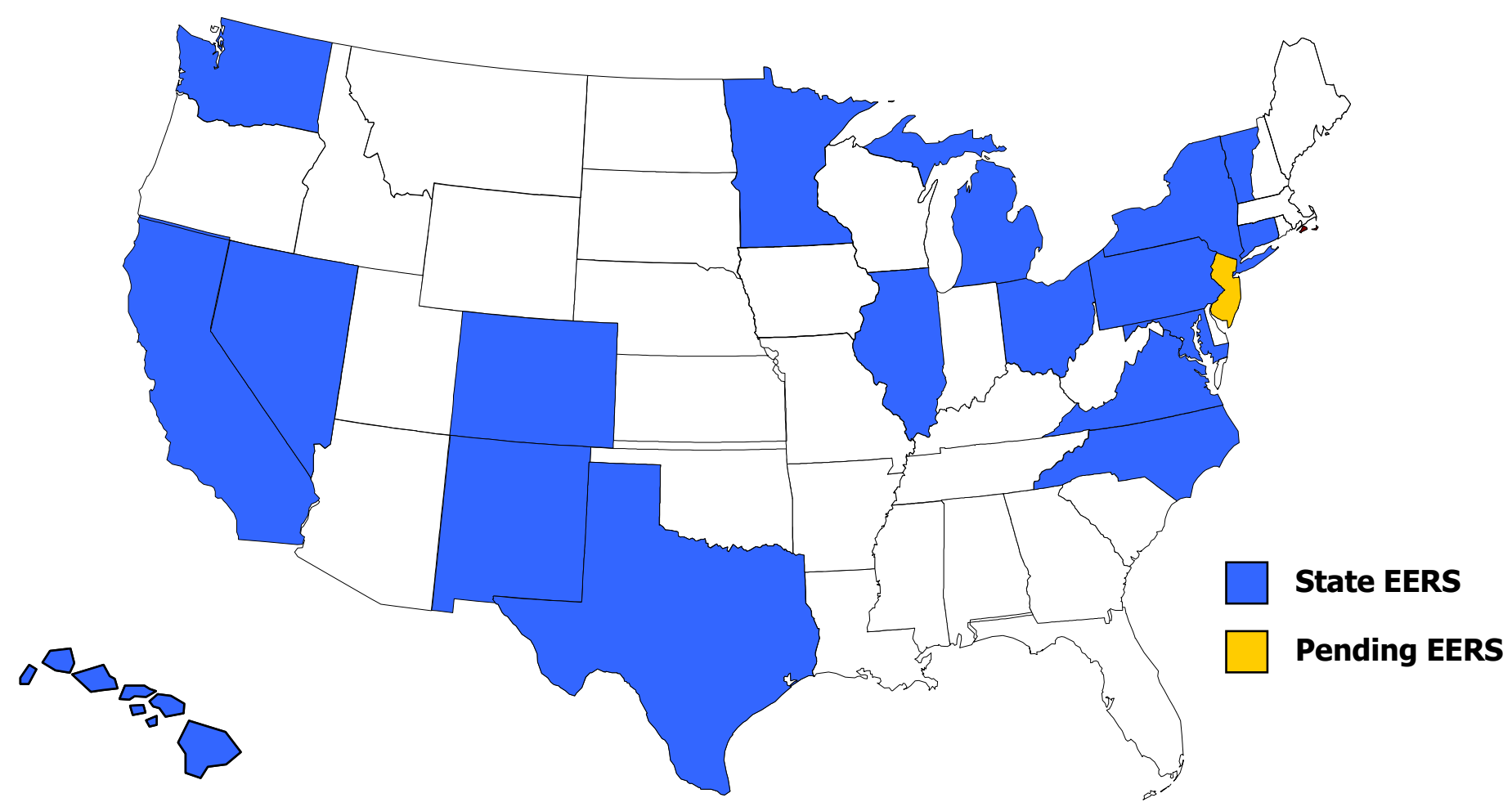

Source: American Council for an Energy-Efficient Economy

Figure 2. States with an EEPS 
Table 1. States with Electricity EEPS Stand-Alone Policies

\begin{tabular}{|c|c|c|}
\hline $\begin{array}{l}\text { State (Date } \\
\text { Enacted) }\end{array}$ & $\begin{array}{l}\text { Obligated } \\
\text { Parties }\end{array}$ & Final Savings Target \\
\hline $\begin{array}{l}\text { California } \\
(2004)\end{array}$ & IOUs & $\begin{array}{l}\text { Electricity: 2,631 GWh/yr (2013) Natural Gas: } 444 \\
\text { MMtherms (2013) }\end{array}$ \\
\hline $\begin{array}{l}\text { Connecticut } \\
(2005)\end{array}$ & $\begin{array}{l}\text { Retail } \\
\text { electric } \\
\text { suppliers }\end{array}$ & $4 \%$ of retail sales $(2010)$ \\
\hline $\begin{array}{l}\text { Colorado } \\
(2007)\end{array}$ & IOUs & $\begin{array}{l}5 \% \text { of both retail sales and peak demand }(2018, \\
\text { cumulatively from measures implemented since 2006) }\end{array}$ \\
\hline Illinois (2007) & $\begin{array}{l}\text { IOUs > } \\
100,000 \\
\text { customers }\end{array}$ & $\begin{array}{l}2 \% \text { of energy delivered (2015) and } 1.1 \% \text { peak demand } \\
(2018)\end{array}$ \\
\hline $\begin{array}{l}\text { Maryland } \\
(2008)\end{array}$ & $\begin{array}{l}\text { Distribution } \\
\text { utilities }\end{array}$ & $10 \%$ reduction in per capita electricity use by 2015 \\
\hline $\begin{array}{l}\text { Michigan } \\
(2008)\end{array}$ & $\begin{array}{l}\text { All electric } \\
\text { utilities }\end{array}$ & $3.3 \%$ of retail sales $(2012)$ \\
\hline $\begin{array}{l}\text { Minnesota } \\
(2007)\end{array}$ & $\begin{array}{l}\text { All electric } \\
\text { utilities }\end{array}$ & $1.5 \%$ of retail sales $(2010)$ \\
\hline $\begin{array}{l}\text { New Mexico } \\
(2008)\end{array}$ & $\begin{array}{l}\text { IOUs and } \\
\text { Munis }\end{array}$ & $10 \%$ of retail sales $(2020)$ \\
\hline $\begin{array}{l}\text { New York } \\
(2008)\end{array}$ & IOUs & $15 \%$ of retail sales $(2015)$ \\
\hline Ohio (2008) & $\begin{array}{l}\text { Distribution } \\
\text { utilities }\end{array}$ & $2 \%$ of retail sales $(2019)$ \\
\hline $\begin{array}{l}\text { Texas } \\
(1997 / 2007)\end{array}$ & $\begin{array}{l}\text { Distribution } \\
\text { utilities }\end{array}$ & $20 \%$ of load growth (2009) \\
\hline
\end{tabular}

Notes:

1) Colorado's natural gas goal has not been set yet.

2) Connecticut's EE requirement is a separate class of measures within the RPS; as such, it functions as a standalone EEPS. $4 \%$ includes electricity, natural gas, and CHP measures.

3) ) At least $1 \%$ of the Minnesota target must be met through utility conservation programs. The other $0.5 \%$ may come from a combination of new appliance standards and building codes, market transformation programs, waste heat recovery, and utility infrastructure upgrades.

4) IOUs are investor-owned utilities.

5) Munis are municipal utilities. 
Table 2. States with Electricity Energy Savings Integrated within RPS

\begin{tabular}{|l|l|l|l|}
\hline \multicolumn{1}{|c|}{$\begin{array}{c}\text { State (Date } \\
\text { Enacted) }\end{array}$} & $\begin{array}{l}\text { Obligated } \\
\text { Parties }\end{array}$ & \multicolumn{1}{|c|}{ Final RPS Target } & \multicolumn{1}{c|}{$\begin{array}{c}\text { Maximum \% that } \\
\text { Can be Satisfied } \\
\text { with Efficiency }\end{array}$} \\
\hline Hawaii (2004) & $\begin{array}{l}\text { All electric } \\
\text { utilities }\end{array}$ & $20 \%(2020)$ & $50 \%$ \\
\hline & $\begin{array}{l}\text { IOUs and } \\
\text { competitive } \\
\text { retail } \\
\text { suppliers }\end{array}$ & $20 \%(2015) ;$ & $25 \%$ \\
\hline $\begin{array}{l}\text { North Carolina } \\
(2007)\end{array}$ & $\begin{array}{l}\text { All electric } \\
\text { utilities }\end{array}$ & $\begin{array}{l}\text { IOUs: } 12.5 \%(2021) ; \\
\text { POUs: } 10 \%(2018)\end{array}$ & $\begin{array}{l}40 \% \text { for IOUs; } \\
\text { unlimited for POUs. }\end{array}$ \\
\hline Ohio (2008) & $\begin{array}{l}\text { Distribution } \\
\text { utilities }\end{array}$ & $25 \%(2025)$ & $50 \%$ \\
\hline $\begin{array}{l}\text { Pennsylvania } \\
(2004)\end{array}$ & $\begin{array}{l}\text { Retail electric } \\
\text { suppliers }\end{array}$ & $10 \%(2020)$ & $\mathrm{n} / \mathrm{a}$ \\
\hline
\end{tabular}

Notes:

1) POUs are publicly owned utilities.

2) In Nevada, nonresidential measures are not to exceed $50 \%$

3) In Pennsylvania, energy efficiency is in a resource tier together with waste coal, large hydroelectric generation, and other "alternative energy" resources. The tier requirement is $10 \%$ by 2020 .

EEPS targets may be expressed as a percentage of demand, peak demand, load growth, or retail sales. In some cases, this is because of varying policy objectives, such as reduction in load growth to reduce the need for new power plants, reduction in peak demand, creating economic opportunity, or often a combination of factors. They vary as well in the types of projects that qualify. In some cases, they include a "weighting" multiplier feature that effectively increases the incentive to implement preferable projects, such as certain types of energy efficiency projects or projects meant to reduce peak load.

Where trading is allowed, utilities required to comply with an EEPS that exceeds that requirement can sell ESCs to other obligated parties that fall short of their requirement. The result, at least in theory, is a less-expensive route to achieve an equivalent amount of savings. Some energy efficiency advocates have argued for a national EEPS with a trading regime that would create a more robust market, bringing broader opportunities for capital to flow to projects (ACEEE 2008). In such a regime, both buyers and sellers of ESCs would have a more robust set of counterparties through which to use the market to meet requirements in a cost-effective manner.

Only four states have introduced ESCs into their EEPS policy - Connecticut, Nevada, Pennsylvania, and most recently Michigan. In only one of the four - Connecticut - have ESCs been actively traded for compliance purposes. Michigan's EEPS, enacted in October 2008, explicitly allows the use of ESCs, called "energy optimization credits," although trading is not allowed initially. ${ }^{9}$ In the EEPS, the Michigan Legislature calls for the state's public utilities commission to establish a certification, tracking, and accounting program for the credits; a date after which energy savings must be achieved to

\footnotetext{
${ }^{9}$ See Michigan Senate Bill No. 213, Sections 83-87.
} 
be considered additional; and a method for allowance for issuance and use of the credits in electronic form.

At least a few other states (North Carolina and Illinois) have opened dockets or are otherwise gathering input on ESC trading for their consideration within an EEPS policy. Because EEPS policies are still very new in the United States, there is little experience from which to draw lessons as to whether ESCs can, and should, help with their compliance. Given the significant role of RECs as a tradable commodity in RPS policies to date and some success with using ESCs for European targets, the question of whether ESCs can play an analogous role for U.S. EEPS compliance is worth exploring. Moreover, bills may be introduced to enact a federal EEPS in the United States in the coming years, or energy efficiency targets within a federal RPS; it is important to understand the way that ESCs work, and their strengths and weaknesses, in those contexts as well.

In 2007, a rejected amendment to the House of Representatives version of what later became the Energy Independence and Security Act (EISA) of 2007 would have created a national EEPS, requiring energy efficiency improvements equal to $10 \%$ of 2019 electricity sales and 5\% of 2019 natural gas sales in 2020. Should a future national EEPS policy be implemented, either within or separate from a national RPS, understanding the relative advantages and disadvantages of allowing utilities to purchase ESCs in addition to, or instead of, implementing their own energy savings programs is particularly important. The lessons learned from existing examples of trading regimes should be applied.

\section{ESC Interaction with RECs and RPS Markets}

ESCs can interact with REC and RPS markets in a number of ways. If ESCs are denominated in MWh units and represent electricity savings, they potentially could be used interchangeably with RECs in voluntary REC markets. Consumers could purchase ESCs to offset each MWh of electricity consumed, similar to how RECs are used by customers today. They also could be used essentially interchangeably with RECs in those compliance markets in which both efficiency and renewables are eligible to meet a single target.

Combined efficiency and renewable energy portfolio targets are a relatively new concept, with most of these policies adopted since 2006. Therefore, experience with these policies is very limited. As discussed earlier, several states have designed policies that establish separate targets for efficiency, while others have established a single target in which efficiency essentially compete on a cost or other basis against renewable energy sources. In Pennsylvania, efficiency is included in a tier of resources with other "alternative energy sources" such as waste coal, large hydro, and certain forms of biomass.

The amount of efficiency stimulated by an EEPS or RPS is a function of the cost of efficiency compared with the resources against which the efficiency competes. The tier structure - and specifically what other resources are in a given tier together with energy savings - is an important design element of any RPS or EEPS policy. 
North Carolina's RPS policy, which places efficiency within a tier of resources including some forms of renewable energy that are expected to be more expensive than the efficiency measures, tends to stimulate the efficiency measures, because they are costcompetitive. A standard similar to Pennsylvania's - where efficiency is included within a tier of resources that also includes lower-cost alternative energy resources such as waste coal, large hydro, and certain biomass technologies - allows obligated parties to take advantage of these lower-cost alternatives and forego or reduce the need to implement efficiency for compliance.

In most states for which energy savings requirements are rolled into a combined RPS, ESCs are likely to trade at lower prices than RECs and will likely replace demand for renewables. This is why certain states capped efficiency to capture energy savings opportunities without sacrificing renewable energy development entirely. Separate tiers for efficiency and renewables are likely to provide more certainty to the market, because the quantities needed of each resource could be more clearly delineated. Such a combination may encourage the adoption of efficiency in the short term and push the development of renewable resources in latter years, delaying the market's ability to develop manufacturing capabilities and infrastructure. Separate tiers would enable the industries to develop in tandem with more market certainty.

In cases where both efficiency and renewables can be used to meet the same standard, the introduction of ESCs could streamline the compliance process through a more liquid market, by combining REC and ESC trading into a single platform and tracking registry. Similar to RECs, ESCs can bring a market mechanism to compliance, which draws funds more easily toward opportunities through competition for the least-cost resources. At least in theory, such a mechanism can reduce compliance costs, enabling more projects and, consequently, the ability to develop more stringent standards.

If ESCs are introduced for compliance, states may need to consider whether to develop a separate alternative compliance payment (ACP) for efficiency. In Connecticut, the ACP for the Class III energy efficiency targets is $\$ 31 / \mathrm{MWh}$, compared to $\$ 55 / \mathrm{MWh}$ for Class I (renewables). However, in situations where both efficiency and renewables are eligible to meet the same standard, then one alternative compliance payment could be used.

Because combined EEPS/RPS policies are in the early stages of implementation, and none of these states have yet incorporated ESC trading, there is little experience with which to derive lessons learned. However, many of these states have implemented REC trading for RPS compliance, so they are well-situated to undertake ESC trading.

\section{Compliance Market Size Potential}

In this section, we estimate the potential U.S. ESC compliance market. Attempting to forecast the size potential for the voluntary market will inevitably be a partly speculative exercise, given the innovative nature of the product and the difficulty in creating valid analogies - most notably the imperfect analogies sometimes made with RECs. 
Although only four states (Connecticut, Pennsylvania, Nevada, and Michigan) currently allow the use of ESCs for compliance, progress in addressing some of the technical and institutional challenges to implementing ESCs could lead to broader adoption among states with long-term energy efficiency savings obligations, and among states with binding greenhouse gas emission targets. Until such time, current U.S. market activity is limited to Connecticut. The market in Connecticut is relatively large, because "Class III credits" (ESCs) are the sole method for EEPS compliance there - for 2008, that requirement was about $627,000 \mathrm{MWh}(2 \%$ of retail sales); the 2009 requirement is $910,000 \mathrm{MWh}$ ( $3 \%$ of retail sales).

As a benchmark for gauging the potential ESC compliance market in the United States, the analysis estimates the ESC market volume under the scenario where all 15 U.S. states with existing long-term energy efficiency obligations allow the use of ESCs for compliance. This estimate could be viewed as an upper bound, because it assumes universal adoption among these 15 states. However, additional states may enact longterm energy efficiency obligations (and/or binding greenhouse gas emission targets) over time, potentially widening the opportunities for ESCs as a compliance instrument. In addition, ESCs potentially could be used for compliance in states without any form of long-term energy efficiency obligation, but where regulators establish shorter-term (e.g., 1 - to 3-year) utility energy efficiency program budgets and savings targets.

Table 3 presents the ESC market potential among the 15 states currently with long-term energy efficiency obligations. We estimate a potential market volume of more than $35,000 \mathrm{GWh}$ in 2010 , growing to approximately $86,000 \mathrm{GWh}$ in 2015 , and $125,000 \mathrm{GWh}$ by 2020 . To put these figures into context, $125,000 \mathrm{GWh}$ is more than one-and-a-half times the total U.S. electric utility energy efficiency savings in 2006, as reported by EIA. ${ }^{10}$ Illinois, New York, Ohio, Michigan, California, and Maryland represent the largest-potential ESC compliance markets among the 15 states, comprising about $77 \%$ of the total market potential in 2020 .

Table 3. Potential ESC Compliance Market in States with Existing Long-Term Energy Efficiency Obligations

\begin{tabular}{|l|r|r|r|}
\hline \multirow{2}{*}{ State } & \multicolumn{3}{|c|}{ ESC Market Potential (GWh) } \\
\cline { 2 - 4 } & \multicolumn{3}{|c|}{$\mathbf{2 0 1 5}$} \\
\hline Stand-alone EEPS & $\mathbf{2 0 1 0}$ & $\mathbf{2 0 2 0}$ \\
\hline CA & 15,491 & 18,654 & 11,021 \\
\hline CT & 1,125 & 1,330 & 1,400 \\
\hline CO & 1,101 & 1,171 & 1,233 \\
\hline IL & 1,604 & 11,441 & 24,449 \\
\hline MD & 2,441 & 7,470 & 10,298 \\
\hline MI & 885 & 6,372 & 11,564 \\
\hline MN & 684 & 4,255 & 7,361 \\
\hline NM & 401 & 936 & 1,604 \\
\hline NY & 6,438 & 16,255 & 21,979 \\
\hline OH & 1,115 & 7,523 & 17,160 \\
\hline
\end{tabular}

${ }^{10} \mathrm{http} / / / \mathrm{www}$. eia.doe.gov/cneaf/electricity/epa/epat9p6.html 


\begin{tabular}{|l|r|r|r|}
\hline TX & 3,193 & 4,463 & 4,769 \\
\hline Subtotal & 33,766 & 80,507 & 114,996 \\
\hline \multicolumn{2}{|c|}{ Energy Efficiency Included in Broader Portfolio Standard } \\
\hline HI & 308 & 878 & 1,316 \\
\hline NC & 0 & 2,713 & 6,902 \\
\hline NV & 1,062 & 2,119 & 2,525 \\
\hline PA & 0 & 0 & 0 \\
\hline Subtotal & 1,370 & 5,711 & 10,742 \\
\hline & & & $\mathbf{1 2 5 , 7 3 8}$ \\
\hline Total & $\mathbf{3 5 , 1 3 6}$ & $\mathbf{8 6 , 2 1 7}$ & \\
\hline
\end{tabular}

General methodology:

(1) Several states (CA, NY, MD and MN) have adopted EEPS policies that encompass policy interventions beyond utility or third-party administered energy efficiency incentive programs - including, for example, building codes and appliance standards. For these states, the values shown in the table reflect only the portion of those broader targets required (or likely) to be met through energy efficiency incentive programs.

(2) States with standalone EEPS policies typically specify their targets in terms of either (a) incremental annual savings as a percentage of retail sales or (b) cumulative savings over some time span as a percentage of retail sales in a given year. To translate these targets into an ESC market volume, we assume that energy efficiency measures installed to meet the standard would be eligible to receive ESCs for ten years following installation, which is consistent with the ESC eligibility period adopted in Connecticut and is in line with typical energy efficiency measure lifetimes.

(3) States that allow energy efficiency measures to qualify as an eligible resource within a broader portfolio standard typically place a cap on the percentage of the total target that can be met with energy efficiency. Except where noted below, we assume that energy efficiency is used for compliance to the maximum extent allowed: $25 \%$ of total portfolio resources in Nevada, $25 \%$ for IOUs in North Carolina, and $50 \%$ in Hawaii.

(4) For most states, GWh targets were derived from percentage targets, which required a retail sales forecast. We developed retail sales forecasts by applying the census region-based growth rates from EIA's 2008 Annual Energy Outlook to actual 2006 retail sales in each state. In deriving the GWh targets from retail sales forecasts, we account for any exemptions included in each state's RPS or EEPS policy (e.g., exemptions for publicly owned utilities or for large customers).

Key state-specific assumptions, conventions, and data sources:

(1) California: The market potential estimate shown for 2010 is based on the 2004-2013 goals adopted for the state's IOUs. The CPUC recently adopted Total Market Gross goals for 2012 -2020, which encompass energy efficiency activities beyond utility programs. The 2015 and 2020 market potential estimates shown in the table reflect only the portion of the Total Market Gross goals achievable through utility programs, as determined in the study (Itron 2008) upon which the goals are based.

(2) Colorado: State law requires that the Colorado PUC establish an EEPS for the state's two IOUs, and specifies the minimum cumulative savings through 2018. The Colorado PUC has established a more-aggressive EEPS for Xcel, but has not yet established an EPPS for the state's other IOU, Aquila. As such, the market potential estimates shown in the table reflect the targets established for Xcel by the Colorado PUC and, for Aquila, the statutory minimum target.

(3) Connecticut: We assume that ESCs from all C\&LM-funded C\&I measures will be used to the extent available (accounting for the 10-year credit life), and that any remaining EEPS requirement will be met through CHP.

(4) New Mexico: The state's EEPS specifies targets for cumulative savings through 2014 and through 2020. To estimate the ESC market potential for 2010 and 2015, we assume a linear ramp-up to the 2014 and 2020 cumulative savings goals.

(5) New York: The values shown in the table for 2010 and 2015 are taken directly from a NY PSC order that developed annual savings targets for utility and NYSERDA-implemented programs, based on the overall statewide EEPS of $15 \%$ reduction by 2015 . The 2020 market potential estimate assumes that programmatic efforts continue past 2015 at the same level as projected for 2015.

(6) North Carolina: Unlike IOUs, publicly owned utilities (POUs) have no cap on the portion of their RPS target that can be met with energy efficiency. In estimating the ESC market potential, we assume that, after all RPS setasides are met and the large hydro allowance (30\%) is fully exhausted, POUs meet $75 \%$ of their residual RPS target with efficiency.

(7) Pennsylvania: The state's Alternative Resource Portfolio Standard has two tiers, one for renewables and another for various "alternative" resources, including energy efficiency, large hydroelectric power, clean coal, municipal solid waste, and various other generation resources. Given that sufficient existing large hydroelectric generation exists to fully meet Pennsylvania's Tier 2 standard, we assume that a market for tradable ESCs is unlikely to develop in that state, and thus the market potential shown is zero for all years.

(8) The Texas EEPS is specified in terms of minimum peak demand savings as a percentage of peak demand growth, and applies only to the state's regulated distribution utilities. We developed a peak demand forecast for the distribution utilities, based on the statewide peak demand forecast in Eliot et al. (2007). We estimated energy savings based on the ratio of energy-to-peak demand savings from energy efficiency programs implemented during 2003-2007 (Frontier Associates, 2008). 


\section{Voluntary Markets}

For several years, energy efficiency advocates and others have touted a voluntary market for ESCs, based on their potential to provide the same level of market flexibility and incentives to energy efficiency opportunities as RECs have to renewable energy. The appeal is especially true for carbon emissions, because the location of the energy efficiency measure reducing carbon emissions makes little difference. The notion is that parties who have exhausted their own opportunities to reduce their energy consumption, or do so cost-effectively, should have a mechanism to reduce their footprint further by supporting projects regardless of geographic location. Capital investment could flow toward the most cost-effective opportunities, competition would be increased along with consumer awareness and demand, and payback times could be shortened to drive forward even the "higher-hanging" fruit.

But despite the promise and the fact that the idea has been discussed for years, a voluntary U.S. market for ESCs has been very slow in developing. There have been some spot transactions, particularly of ESCs in the form of carbon offsets. In this form, the energy savings can be certified by credible third parties through established protocols not yet available to ESCs in noncarbon contexts. But there has been neither momentum nor structural support for a standalone ESC voluntary market. There are at least four significant reasons why the voluntary ESC market has not yet become a significant market tool in the United States, compared with the robust voluntary REC market of more than 10 million purchased MWhs per year.

The first is communicating the value proposition. Much has been written about this difficulty with respect to RECs. But ESCs as a tradable commodity may be a more difficult concept to communicate (and therefore to market) than even RECs, their renewable energy counterpart. ESCs may find difficulty with an additional hurdle RECs have not faced: public acceptance of the notion of taking action that results in saving money, and then turning around and selling the proof of that savings for yet more income. Is this an unwarranted double benefit?

In a time when institutional energy users are highly motivated to reduce their carbon footprint and "green" their public brand, a purchase of RECs to displace electricity use is a fairly straightforward means of accomplishing both. Although energy efficiency is at least as effective a means, the buying, and especially the selling, of the results of energy efficiency measures in certificate form could invite stakeholder scrutiny or accusations of "greenwashing."

At the least, voluntarily buying or selling ESCs would tend to generate a level of confusion and scrutiny aimed at market participants that would not apply to a company merely deploying its own energy efficiency program and "keeping" the certificates that demonstrate saved energy. For example, could a seller claim its energy savings for branding or carbon purposes? Or, would a buyer choosing ESCs over more costly energy efficiency measures that would have affected its own operations want to make energy savings claims under those circumstances? Both scenarios could invite the possibility of 
negative attention during a time when many companies are paying close attention to both their carbon footprint and the greenness of their brand.

Second, as has been discussed, measuring and verifying energy savings always comes with challenges. But voluntary markets tend to be national instead of confined to states or smaller geographic regions, increasing the risk that a given ESC, or a MWh of savings for a given project, does not carry the same value to the buyer as it does to the seller. For example, the same project could have a shorter payback period in one region of the country, where energy prices are higher, than in another region. Voluntary markets may require even more stringent additionality requirements than compliance programs, particularly if the ESCs are procured for their carbon benefits. If consumers voluntarily pay a premium for the ESCs, they need some assurance that they are supporting efficiency measures and savings that would not have otherwise occurred. Otherwise, consumers simply may be helping the bottom line of corporations where efficiency measures are installed, without actually driving the development of new projects.

The third reason, related to the second, is the fact that no objective third party has stepped into the role of "certifying body" to address M\&V and additionality issues, on a de facto if not officially recognized basis. Because of the scrutiny that can come on the voluntary side, certification is particularly important, as it has been for voluntary REC markets. Environmental Resources Trust-Winrock has promulgated a set of draft rules for the voluntary market, with an ESC certification called "Ecopower," including a model "certification template." As of September 2008, ERT-Winrock has not yet certified any transactions and was still in a comment period for the model rules.

Fourth, the ESC voluntary market has not yet received the comparable boost from compliance markets that significantly helped the U.S. REC market. During the early development of U.S. REC markets from 2000-03, marketers were unsure whether RECs would enjoy longevity in the market, given the innovative nature of the product and the challenge in communicating its value proposition to consumers. At the time, a slowly increasing voluntary demand for RECs likely played some role in their early use by states as a vehicle to facilitate RPS compliance. But with the benefit of hindsight, evidence of the converse seems clearer: It is most likely that states' legal sanction of RECs for compliance purposes lent the credibility that RECs needed to increase buyers' comfort levels, which allowed the product to gain a lasting foothold in the voluntary market. For example, when the New England states and Texas first elected to use RECs for RPS compliance in 2002, the entire U.S. voluntary market for certified RECs was less than $80,000 \mathrm{MWh}$; by the end of 2003, that figure had increased nearly fivefold (Bird and Swezey 2004).

\section{New York Voluntary ESC Pilot Program}

The New York State Energy Research and Development Authority (NYSERDA) is developing a pilot voluntary ESC program, which it expects to officially launch with its first ESC auction by spring 2009. The program is designed to create environmental benefits by increasing the implementation of energy efficiency measures, improving the transparency and credibility of ESC markets, and addressing potential emissions 
"leakage" (i.e., shifting power generation to outside of the regulated region) that could undermine the goals of the Regional Greenhouse Gas Initiative (RGGI), for which New York is a participating state.

Under the program, NYSERDA is aggregating ESCs from qualifying energy efficiency projects, auctioning them to brokers or consumers, and using the proceeds to fund additional energy efficiency projects. The revenues from the ESC sales will supplement funds available under NYSERDA's public benefit fund program for energy efficiency. Historically, the fund was known as the "Peak Load Reduction" Program; it is currently being redesigned and will be relaunched as the "Existing Facilities" Program. Once the ESC program is operational, efficiency projects installed through the NYSERDA programs may sell ESCs equivalent to the calculated savings. In this way, the sale of ESCs should increase energy efficiency implementation, both in terms of size and number of projects.

NYSERDA plans to use the measurement and verification (M\&V) system already in place for its existing energy efficiency program to determine the savings and number of ESCs issued for projects. Therefore, the ESC program will require very little additional cost with respect to $\mathrm{M} \& \mathrm{~V}$, but it is expected to be well-served by NYSERDA's robust project database and rigorous established protocols. One of the stated goals of the program is to ensure that savings are scrutinized and determined to be real and additional. Savings for small projects are calculated based on deemed savings, while medium projects require engineering analysis; and large projects require both an engineering analysis and actual measurement (e.g., using data loggers).

To minimize transaction costs, the number of ESCs granted to a project will be estimated over the expected lifetime of the efficiency measure and issued in the first year of operation of the measure. The savings will be discounted for free ridership (i.e., projects that would have been installed without the incentives provided through the program or may be done for nonenergy-related reasons). NYSERDA plans to develop a standard set of guidance on the expected lifetime of various measures based on previous experience with efficiency projects and technology turnover.

To initiate the program, NYSERDA began aggregating ESCs from customers in the Peak Load Reduction Program during summer 2007. All of the participants voluntarily agreed to donate the environmental benefits associated with the efficiency projects to NYSERDA, which will enable the group to auction them as ESCs. As of May 2008, NYSERDA had acquired about 200,000 MWh of energy savings from roughly 800 to 900 individual projects, mainly at commercial facilities. As of July 2008, program administrators were developing a full plan for the auction program, including decisions about ownership of the ESCs. They also were determining whether the benefits of the ESCs would be held in escrow and retired on behalf of ESC purchasers or whether the ownership of the attributes would be transferred.

To address double-counting, NYSERDA plans to initially rely on attestations from brokers that the ESCs will not be double-sold. Eventually, tracking of ownership and 
retirement of ESCs may be integrated into an automated REC tracking system, which is currently under development for New York.

One of the main drivers of the program is its potential to use energy savings to reduce carbon emissions leakage from the RGGI cap-and-trade program. Although the program design does not assign carbon benefits directly to energy efficiency projects, these projects can provide carbon emission reductions to the extent that they can reduce emissions leakage. Within the competitive generation region covered by RGGI, which includes New York State, there is a total cap on carbon emissions from electricity generation. Leakage occurs when generation shifts from sources subject to RGGI caps to those outside the RGGI region that are not subject to the cap, which results in a potential net increase in carbon emissions when the uncapped plants export energy into New York and other RGGI states. With no cap, the power plants outside of RGGI have a competitive cost advantage over the plants within RGGI. NYSERDA is deriving a methodology of measuring the potential leakage reduction that energy efficiency projects could provide.

There are several key features to be culled out of the NYSERDA program and potentially emulated by other states' systems benefit fund administrators who want to use ESCs to make limited funds go further. Most important, NYSERDA is relying on its existing efficiency programs and infrastructure to provide a foundation for credible ESCs. It is leveraging the existing $\mathrm{M} \& \mathrm{~V}$ data and protocols to minimize transaction costs and to streamline the process of verifying and issuing ESCs. In this way, the NYSERDA program is a model that could potentially be replicated by other funds that are devoted to implementing efficiency measures.

Arguably, the NYSERDA program is not a pure voluntary ESC market in the true sense. Unlike a straightforward voluntary market, the supply is predetermined and preaggregated. But unlike a compliance market, buyers are voluntary and demand is not fixed and constant. NYSERDA might perhaps be best characterized as an inversion of the normal compliance market model, in which regulatory mandates/goals create a supply of ESCs, and the market provides the demand. Perhaps, then, this kind of model provides some sort of pathway to creating a true voluntary ESC market, by addressing the development and communication of a value proposition, defining customer classes, and learning about and overcoming obstacles to customer and stakeholder acceptance. At the same time, the NYSERDA program addresses another problem that states face: meeting aggressive energy savings and/or carbon reduction goals while limiting the impact on ratepayers. One of the appeals to the program is that it encourages private participation in ESC markets while addressing the concern some buyers might have about supporting another person or entity's private economic benefit; at least in part, the NYSERDA model instead supports stretching public benefits dollars farther.

Early examples of voluntary activity (see also Other Voluntary Activity: IBM) with ESCs suggest an emerging interest to coincide with the renewed broader interest in the importance of energy savings. However, for the voluntary market to build momentum, there is a need for an independent, national certification body. Voluntary markets also 
can benefit from lessons learned in compliance markets, particularly with regard to $\mathrm{M} \& \mathrm{~V}$ protocols and certification processes.

\section{Other Voluntary Activity: IBM}

In the private sector, IBM launched another kind of pilot program to create the market flexibility that ESCs can provide and help move projects forward in their clients' energyintensive data centers. Because of cooling and other equipment needs, these operations require as much as 15 times more energy per square foot than a typical office building.

In November 2007, IBM created a relationship with Neuwing Energy Ventures to help measure energy-reduction measures and create certificates from the reductions. The goal is to make the efficiency certificates program available to users of IBM's systems and data storage offerings, providing clients with the option to either keep and retire the certificates or make them available for purchase, first in the United States and later in Europe. The certificates program is part of IBM's \$1 billion per year "Project Big Green" initiative, aimed at increasing the efficiency of IBM products as well as delivering technologies that help customers increase energy efficiency in their data centers and physical plants.

Under the program, Neuwing first establishes an energy consumption baseline for an interested data center based on industry estimates for the servers and the data center's energy profile. The energy decision maker for the center can then choose from several preidentified projects aimed at reducing electricity consumption in data centers, including the use of virtualization technologies to reduce the number of physical systems and methods for correcting design flaws. Once the measure is implemented, Neuwing creates certificates based on the savings (MWh) and keeps a portion of the certificates or a "per MWh-saved" fee in exchange for their assessment services. It is too soon to gauge the effectiveness of the IBM program, but its outline presents an interesting set of ideas for a very important sector of the energy efficiency market.

\section{Carbon Market Interaction}

Efficiency has played a substantial role in international carbon offset markets, comprising $18 \%$ of the global voluntary carbon offset transactions in 2007 (Hamilton et al. 2008). Energy savings have begun to be traded as voluntary carbon offsets in the Chicago Climate Exchange (CCX) - a trading platform through which businesses or institutional entities commit to GHG emissions reductions and trade with one another to meet their target - and through a small number of bilateral transactions. As of this writing, there are six energy efficiency-based offset projects registered on the CCX out of 106 total registered projects.

Going forward, one key to the value of ESCs in these markets will be how seamlessly they can be integrated, or "converted" into offsets, so that the same ESC instrument can participate in voluntary ESC or carbon markets. While energy savings clearly offer carbon dioxide $\left(\mathrm{CO}_{2}\right)$ emissions benefits and may be a key strategy in achieving $\mathrm{GHG}$ mitigation goals, their role in carbon markets will be shaped by the design of future policies and, in the interim, by standards adopted for voluntary markets. Emerging compliance markets could be the largest opportunity for ESCs, especially in the event of a federal carbon cap-and-trade program, as has been proposed. 


\section{Direct Versus Indirect Emissions}

Besides additionality requirements, which apply to any ESC market but have been particularly important in carbon markets, another key issue for efficiency is that it creates an indirect emission benefit by reducing the need for conventional generation, compared with direct emission reductions, such as those achieved by installing pollution controls on industrial factories. Therefore, there are questions as to whether efficiency measures can or should be used to offset direct emissions. REC policy makers grapple with the same issue: RECs, which also can reduce indirect but not direct emissions, are generally accepted as offsets for conventional power purchases, but there is ongoing debate over whether they can be used to offset direct GHG emissions.

The emissions reductions associated with the efficiency measure depend on the type of generation that is displaced (e.g., whether it is natural gas or coal). The fact that efficiency creates an indirect emission reduction benefit also makes it unclear whether efficiency can claim the property right to the emission reduction. The issue of ownership likely will be clarified when carbon regulations are adopted; but, in the interim, there continues to be debate about ownership and the extent to which sources that provide indirect emissions benefits can be used as offsets of direct carbon emissions, especially in regions where caps are expected.

\section{Carbon Cap and Trade}

Carbon regulation is indeed beginning to emerge in the United States, and the shape of these policies will have ramifications for how ESCs can interact in carbon markets going forward. When it takes effect in 2009, the Regional Greenhouse Gas Initiative (RGGI), which involves 10 Northeast states, will be the first cap-and-trade program established in the United States. There also are two regional programs under development in the West and the Midwest. The Western Climate Initiative, which involves seven Western states and four Canadian provinces is developing rules. And finally, the Midwestern Greenhouse Gas Reduction Accord, which involves approximately a dozen Midwestern states, also is developing cap-and-trade systems. A program also is being debated at the federal level.

In the cap-and-trade programs that have been developed in the Northeast (RGGI) and in Europe, allowances have been provided only to direct emitters and not to indirect emission reduction measures such as efficiency. Thus, while efficiency provides emissions benefits and will make it easier to comply with the cap, efficiency measures do not affect overall carbon emissions because the emitters will simply use any allowances that are freed-up by the efficiency measures to meet the cap. While they have not been adopted in these programs, set-asides or other allocation measures may be used in capand-trade programs to credit indirect emissions sources that provide emissions benefits (such as efficiency), which would potentially enable ESCs to play in carbon markets (Bertoldi et al. 2005, Bird et al. 2007). Set-asides for renewables and efficiency have been used in some NOx cap-and-trade programs and a set-aside was recently proposed in federal climate legislation (Jacobson and High 2008). Load-based caps also may enable efficiency to participate in carbon markets (Hamrin et al. 2007). Because most U.S. cap- 
and-trade programs are in the early stages of development, it is unclear how efficiency measures will be treated.

While the RGGI program does not specifically grant carbon emission allowances to efficiency measures, some argue that efficiency can still play a role in providing overall reductions to the extent that it prevents leakage - the idea that caps may cause power generation to be shifted to high-emitting plants outside of the regulated region. Leakage is a particular concern for regional cap-and-trade programs and, if it occurs, overall emission reduction targets may not be fully realized; rather, emissions may simply be shifted to other regions. Energy efficiency may be able to play a role in addressing leakage by reducing cost pressures to meet the cap. As discussed earlier, the NYSERDA voluntary pilot ESC program is predicated on this theory that energy efficiency will result in carbon emissions reductions by reducing imports into the region.

\section{ESC Trading in Connecticut}

For U.S. EEPS policy makers and those seeking to understand the prospects for broader U.S. ESC compliance trading, the ESC trading program in Connecticut merits attention; at the time of this writing, it is the only U.S. state with active ESC trading. ${ }^{11}$ As the experience of a U.S. state, lessons from Connecticut can be more applicable than European examples to the circumstances and challenges of other EEPS states considering trading.

Connecticut expanded its RPS in 2005 (via Public Act 05-01,"An Act Concerning Energy Independence") to include an energy efficiency portfolio standard, called "Class III," to meet a $1 \%$ energy efficiency savings target for 2007 , ramping up to $2 \%$ for $2008,3 \%$ for 2009 , and $4 \%$ for 2010 and thereafter. ${ }^{12}$

The targets include a broad array of eligible savings projects, including combined heat and power (CHP), as well as load management and demand response. The Connecticut Department of Public Utility Control (DPUC) serves as the certifying body, approving projects for Class III credit issuance on a quarterly basis.

In 2007, Public Act 07-242, “An Act Concerning Electricity and Energy Efficiency," expanded the eligible savings measures to include certain waste heat recovery systems. In September 2008, a proposed expansion of the act was drafted to encompass residential measures (DPUC 2008). As of this writing, discussions on that draft decision are still underway and a decision has not yet been made on key features, such as the cutoff date for residential measures, prior to which the measures will be ineligible.

Obligated suppliers can purchase Class III credits to meet their obligations on a quarterly basis; ESCs are issued each quarter for each project over the life of the project, with a maximum of 10 years. To the extent that obligations are not met, suppliers must pay 3.1

\footnotetext{
${ }^{11}$ As of July 2008.

${ }^{12}$ Each calendar year's target must be met by January 1 of the following year.
} 
cents/kWh in the form of an ACP set by the DPUC. By way of comparison, the Class I and II ACP (for renewables) is statutorily set at 5.5 cents $/ \mathrm{kWh}$. To guarantee a market for the credits, there is an established floor price of $1 \mathrm{cent} / \mathrm{kWh}$ for the credits. This floor price may become significant in the event of an over-supply of ESCs that could otherwise drive down the price and undermine the value of the program.

Market value is a key indicator for considerations of market size. Although credit prices are under cover of contract, information on average or median prices is not confidential. One of the ESC providers in Connecticut, United Illuminating, reports an average price in the roughly 2-year-old market of about $\$ 20 / \mathrm{MWh}$, and broker bulletin boards during the same period show that the ask price for ESCs has ranged from about \$20-28/MWh. ${ }^{13}$ By contrast, prices in the Italian regime are somewhat lower; in fact, the weighted average price of Type 1 EEC (electricity savings) in Italy dropped from about 77 Euro/toe (which equates to about $\$ 9.05 / \mathrm{MWh}$ ) to 47.7 Euro/toe (about $\$ 5.60 / \mathrm{MWh}$ ) over the period from 2006 to 2007 (Pavan 2008).

\section{Context for the Connecticut ESC Program}

It is important to understand not only the rules in Connecticut, their rationale, and how well they are working, but also the context in which ESC trading was created in the state. ${ }^{14}$ Connecticut's unique circumstances likely played a significant role in the state legislature's initial decision to implement an ESC trading regime. The context also helps explain the reasons for the various implementation rules of the Class III Credits program promulgated by the Connecticut DPUC.

First, Connecticut is one of the U.S. states that has been deregulated, or restructured, for retail electricity. So unlike several other EEPS states that are regulated and have generally only a few investor-owned regulated utilities responsible for most EEPS compliance, Connecticut has more than 20 competitive suppliers (load-serving entities, or LSEs) responsible for a share of EEPS compliance. ${ }^{15}$ Unlike regulated states, the large numbers of competitive load-serving entities are not utilities with energy efficiency experience administering public benefits funds. Many of them are energy marketers and traders who do not possess this type of experience.

Conversely, the two major Connecticut distribution utilities - United Illuminating (UI) and Connecticut Power \& Light (CL\&P) - had been administering the energy efficiency programs paid for by public benefit funds, with DPUC oversight, since 2000 (for about five years prior to the enactment of the EEPS). They were positioned to continue to implement the vast majority of savings measures for EEPS compliance.

\footnotetext{
${ }^{13}$ Indicative pricing information can be obtained from ICAP at http://www.icap.com/ and from Evolution Markets at http://new.evomarkets.com/.

${ }^{14}$ Some background may also be helpful context for the Connecticut program. Because of state budget problems in 2003, the Connecticut state legislature took over part of the fund through a bond issue. The fund became partly securitized, and a little more than $25 \%$ of the ratepayer charge normally used to fund energy savings projects was used, for a time, to pay off the debt.

${ }^{15}$ WattsNewCT. "Suppliers and Aggregators." Electric Restructuring. http://www.wattsnewct.com/newsuppliers.html. Accessed August 21, 2008.
} 
Although the various suppliers are free to fund and implement their own energy savings activities for EEPS compliance (see Figure 3), to date they primarily have opted to buy ESCs from those issued through the Conservation and Load Management (C\&LM) fund administered by UI and CL\&P. UI and CL\&P do not have their own Class III obligations under the Connecticut restructuring rules, but they are the largest sellers of Class III credits in the state by far.

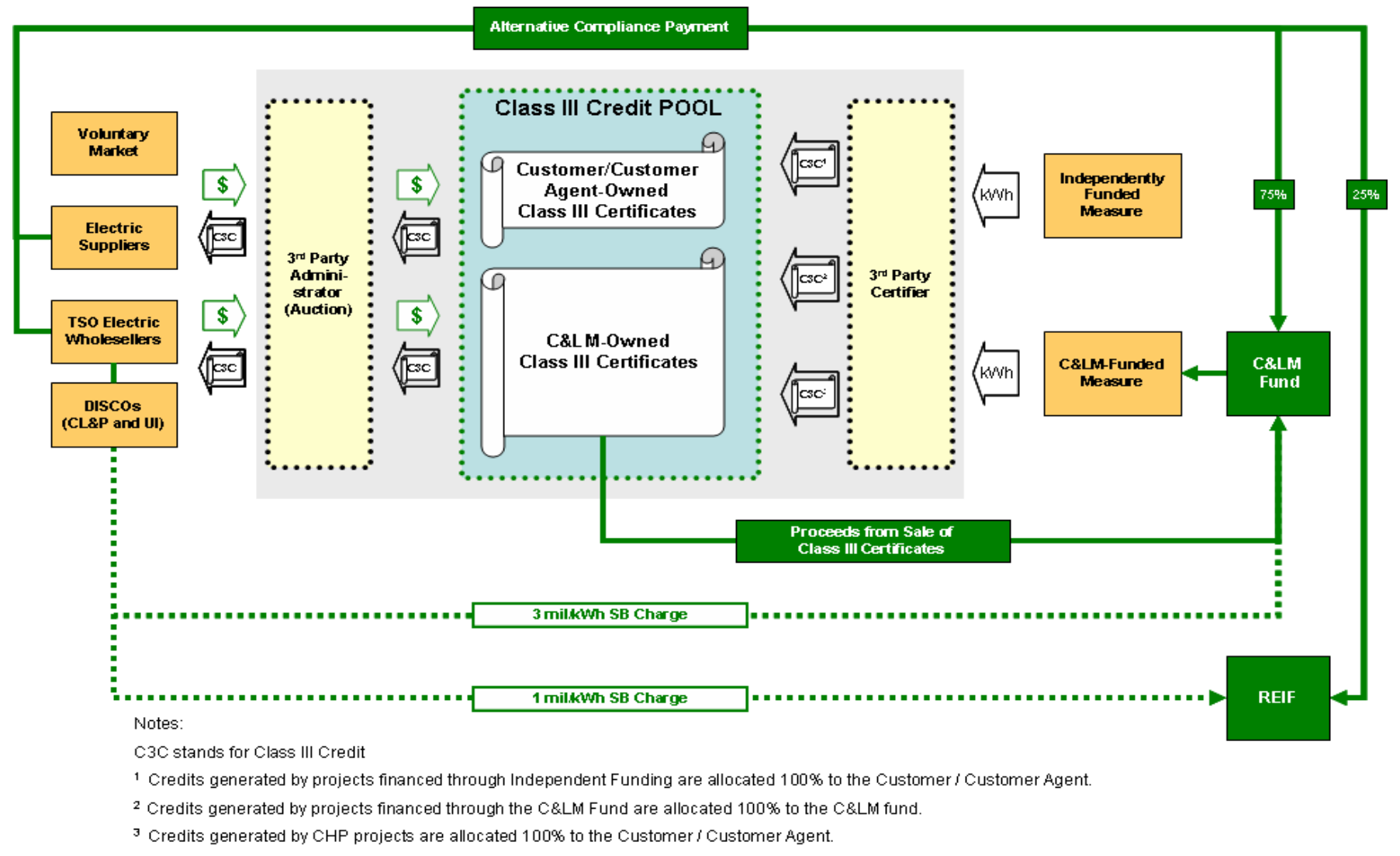

Source: Connecticut DPUC

Figure 3. The flow of ESCs in the Connecticut Compliance Trading Scheme ${ }^{16}$

\footnotetext{
${ }^{16}$ State of Connecticut Department of Public Utility Control. Docket No. 05-07-19, DPUC Proceeding to Develop A New Distributed Resources Portfolio Standard (Class III), February 16, 2006.

http://www.ct.gov/dpuc/cwp/view.asp?a=3354\&q=415186
} 


\section{Trading Experience}

For the most part, the Connecticut ESC market mechanism is working as intended: The independent suppliers are complying with the EEPS policy with their most cost-effective option, which is buying credits (ESCs), primarily from UI and CL\&P, the two major investor-owned distribution utilities without Class III obligations of their own. Credits derived from C\&LM-funded projects, administered by the two utilities, comprise the lion's share of the market. ${ }^{17}$ These credits are sold to the suppliers through the quarterly auctions. ${ }^{18}$

So the effect of the Class III program generally has been that those entities in the best position to implement Connecticut energy savings programs - CL\&P and UI - are doing so. At the same time, other suppliers are meeting their obligations by buying the credits, the proceeds of which circle back to support the C\&LM fund to feed future projects and optimizing the state's ability to meet its targets. The credits sold by the distribution utilities on behalf of Connecticut's electric ratepayers return dollars to the funding stream.

Table 4 shows the New England Generation Information System (NEPOOL GIS) trading volume summary for a recent quarter. Because the system was already functioning prior to the Connecticut trading scheme's implementation, Connecticut's choice to "piggyback" on to the NEPOOL GIS energy generation tracking system was a key leverage point in the state's efforts to reduce transaction costs. Connecticut parties can use the NEPOOL GIS to track, trade, and settle Class III Credits online at www.nepoolgis.com. The data in the table, accessed in September 2008, showed about 77,000 Class III credits, all of which were derived from the C\&LM fund. ${ }^{19}$ Each credit denotes $1 \mathrm{MWh}$ of energy savings.

\footnotetext{
${ }^{17}$ This is the case regardless of whether measured in MWh, number of projects, or number of energy savings measures.

${ }^{18}$ Bruno, Steve. CL\&P. Personal Communication. August 4, 2008. Mascola, Fred. UI. Personal Communication. July 31, 2008.

${ }^{19}$ https://www.nepoolgis.com/myModule/rpt/myrpt.asp?r=107\&TabName=Certificate. This quantity should not be construed as the full amount available for that quarter, simply the amount listed as traded.
} 
Table 4. Example of NEPOOL GIS Trading Activity

\begin{tabular}{|l|r|}
\hline & \multicolumn{1}{|l|}{$\begin{array}{l}\text { Number of } \\
\text { Certificates } \\
\text { Fuel }\end{array}$} \\
\hline Solar photovoltaic & 762 \\
\hline Fuel cell & 3,227 \\
\hline Digester gas & 9,096 \\
\hline Efficient resource (Maine) & 50,934 \\
\hline CLM & $\mathbf{7 6 , 7 4 3}$ \\
\hline Wind & 181,798 \\
\hline Landfill gas & 252,799 \\
\hline Biomass & 320,371 \\
\hline Municipal solid waste & 340,409 \\
\hline Wood & 489,610 \\
\hline Trash-to-energy & 532,365 \\
\hline Jet & 547,315 \\
\hline Diesel & 813,650 \\
\hline Oil & $1,093,789$ \\
\hline Hydroelectric/hydropower & $2,526,166$ \\
\hline Coal & $4,912,296$ \\
\hline Natural gas & $8,745,525$ \\
\hline Nuclear & $9,608,300$ \\
\hline Total & $\mathbf{3 0 , 5 0 5 , 1 5 5}$ \\
\hline
\end{tabular}

Source: NEPOOL GIS, https://www.nepoolgis.com/myModule/rpt/myrpt.asp?r=107\&TabName=Certificate. Note: Emphasis added.

The total Connecticut Class III requirement for calendar year 2008 - enough to cover $2 \%$ of retail sales - is about $627,000 \mathrm{MWh}$. The available information on approximate eligible quantities of these credits derived from the C\&LM for both 2007 and 2008 is in Table 5.

Table 5. C\&LM Class III Credits Available from CL\&P and UI (MWh)

\begin{tabular}{|l|r|r|}
\hline & $\mathbf{2 0 0 7}$ & $\mathbf{2 0 0 8}$ \\
\hline CL\&P Residential Savings & 178,500 & 257,500 \\
\hline $\begin{array}{l}\text { CL\&P Commercial and Industrial } \\
\text { Savings }\end{array}$ & 368,000 & 483,000 \\
\hline UI Total Savings & 98,000 & 110,000 \\
\hline $\begin{array}{l}\text { Expected Available from CL\&P } \\
\text { and UI, Combined }\end{array}$ & 644,500 & 850,500 \\
\hline Expected Total State Obligation & 300,000 & 627,000 \\
\hline
\end{tabular}

Sources: CL\&P, UI, and the 2009 C\&LM Plan submitted jointly by the two companies. Note: All data points are rounded approximations. 


\section{Program Structure and Lessons Learned}

Several of the structural elements in the Connecticut trading scheme support a reduction in the utilities' administrative burden and transaction costs. For the first 18 months of the program, the emphasis was on streamlining the way that ESCs were issued and traded for compliance, keeping it simple with the idea that the program could be expanded later. In July 2008, about six quarters into the compliance period for the EEPS, some of these simple rules are being revisited.

There are several examples demonstrating this approach toward establishing clear, simple rules meant to keep the difficulty of compliance, administrative burdens, and transaction costs to a minimum. ${ }^{20}$ Perhaps the most important example is one of good fortune as much as good planning. The DPUC was able to work with NEPOOL, APX, and other pertinent stakeholders to piggyback the tracking of credit ownership through the GIS, an automated system that was already in existence for tracking RECs in New England. The GIS tracks parties' transfer of credit ownership, establishing a traceable record of the chain of ownership for the Class III credits. The paper-free Web-based platform allows these tasks to be accomplished at a low cost.

Another example of a rule that helps ease the administrative burden is that the two major utilities - which together administer the fund that creates the vast majority of the credits do not need to receive DPUC approval for every project's M\&V. Rather, they each submit an annual "blanket" plan for all of the expected efficiency projects, with M\&V incorporated into that plan. The DPUC approves the entire plan at once, and then the utilities enter data into the GIS accordingly, so that credits are created quarterly as they are actually generated. The utilities also report on the generation of REC credits and sales on a quarterly basis to the DPUC. But there is no need for quarterly M\&V approval, because that is covered through the annual process. ${ }^{21}$

\section{Ironing Out Residential Rules}

Residential projects typically require aggregation and a deemed savings measurement approach; large commercial and industrial measures are easier to measure and track. That is the strong rationale for excluding residential measures in the initial period, a takeaway for other states to consider. But once about 18 months of market experience was complete, the DPUC included residential measures in the Class III eligibility.

Still another example of simplifying Class III trading is that the DPUC also established a kind of one-size-fits-all approach to ownership of the proceeds of sold credits. Rather than attempting to work a split in proceeds for C\&LM-funded projects, $100 \%$ of those proceeds went back into the C\&LM fund. Similarly, the way the rules are currently structured, $100 \%$ of proceeds from independently funded projects go to the source of that funding. The $100 \%$ rule (in both its forms) is one of the rules being revisited.

\footnotetext{
${ }^{20}$ Even with the DPUC rules established to simplify compliance, inevitable challenges have arisen. For example, there have been obligated parties that missed opportunities to buy Class III certificates because, in some cases, they were not aware of the existence of the auctions within the time frame they were occurring.

${ }^{21}$ The utilities' M\&V plan is called the "Program Savings Document."
} 
Because energy end users typically fund part of the cost of C\&LM-funded energy savings projects on their own sites, the DPUC reviewed the possibility of returning $25 \%$ of the proceeds to the end user. ${ }^{22}$ This was the arrangement that the statute directed, reviewed by the DPUC in August 2008 as part of its rules promulgation for residential measures' inclusion. ${ }^{23}$ In the conception of the $75 / 25$ split, there was deference to the value of not overcomplicating such a split by attempting anything more complicated than a 75/25 proceeds split for every C\&LM project. There has been no attempt, for example, to introduce different proceeds split formulas for different projects types.

But the DPUC ultimately determined that even the $75 / 25$ split could introduce a new administrative burden, in that it could require the CL\&P and UI to backtrack their pool of Class III credits to the customers participating. This was a significant concern for program administrators at UI and CP\&L, because the legislation technically allows the DPUC to structure the return of proceeds from ESC sales in a way that would be tough to administer. For example, if customers purchased lighting fixtures, the utilities would not want to be in the position of reimbursing that customer for $25 \%$ of the ESC proceeds on a quarterly or even annual basis over the lifetime of the savings measure.

With the aim of not adding such administrative layers to the running of the Class III program, the utilities took the position that a good compromise might be to return the $25 \%$ to the ratepayers at large. This would avoid the need to track up to 10 years' worth of credits to the specific customers on whose sites the measures were implemented, which the utilities view as too difficult and time-consuming. They proposed instead to simply reimburse all ratepayers by adding the reimbursement into federally mandated congestion charges in the customer bill. This would give deference to the fact that customers are paying for some portion of the savings measures, without adding the burdensome responsibility of trying to track proceeds back to individual projects.

Ultimately, the DPUC decided to allocate $100 \%$ of Class III credits to the C\&LM program, allocated to residential programs, "as a means to continue to fund the benefits that residential customers receive from the C\&LM-funded residential programs." They decided against what the distribution utilities referred to as "a plethora of administrative headaches associated with allocating $25 \%$ of Class III credits to residential customers" on to the program administrators. Important for program designers in other states, the DPUC cited the small energy savings accrued per customer and the many thousands of customers to track, the transient nature of some customers, and split benefits in rental properties. The DPUC concluded that allocating the $25 \%$ Class III credit on a percustomer basis was "plainly infeasible." They directed the distribution utilities to report their residential allocations in their annual C\&LM filing submitted to the DPUC. In the same proceeding of September 2008, they further directed that market participants who participate in C\&LM programs and who aggregate more than $100 \mathrm{~kW}$ of residential load

\footnotetext{
${ }^{22}$ For example, if the C\&LM funds an equipment upgrade, the customer would typically buy the equipment and be reimbursed fully for the additional incremental expenditure for buying more expensive energyefficient equipment.

${ }^{23}$ Conn. Gen. Stat. § 16-243t(c)
} 
may receive $25 \%$ of the Class III credit allocation. Lastly, they directed that independently funded residential projects will receive $100 \%$ of the value of the Class III RECs generated by the projects.

\section{Other Notable Provisions}

At least two of the Connecticut rules are somewhat unusual and particularly worth watching over time to note how they affect the success of the program; after only four auctions to date, it is still too early to say. The most important is the inclusion of CHP projects. Every MWh generated at a CHP plant that came online after January 1, 2006, with an overall efficiency level of at least $50 \%$ and with useful electrical energy that is at least $20 \%$ of the total output qualifies. Because the plants will generate large quantities of eligible credits, some stakeholders have anticipated that the inclusion of CHP will make the targets too easy to attain and result in fewer non-CHP efficiency projects, because CHP is likely to be the most cost-competitive way to meet the requirements. Some of the CHP projects may not have been built as a direct result of the EEPS but may be receiving an extra benefit from its subsequent implementation.

For example, at least one eligible plant at a paper mill has a capacity of about $30 \mathrm{MW}$, meaning it will likely generate more than $175,000 \mathrm{MWh}$ per year, or more than $25 \%$ of the credits required for the entire 2008 overall Connecticut obligation. The ability to trade credits makes all of those credits eligible and will likely keep the price for credits down. Many expect that the CHP rule, in particular, will cause an oversupply of credits by the time the requirement flattens out at 4\% in 2010 for each year after that, creating downward price pressure. But many RPS requirements around the country have been revisited and increased over time for similar reasons; that is the expectation of some in the Connecticut Class III situation as well.

The other legislative rule worth noting and tracking is the establishment of a floor price of $\$ 0.01 / \mathrm{kWh}$ for the credits, limiting the open-bidding process. The price protection seems designed to ensure that the risk of oversupply does not degrade the value of the credits and hurt the long-term health of the market, a stop-gap measure to help keep the market stable if the targets turn out to be low, especially considering the availability of CHP credits. But the floor also can have the effect of limiting the free market's ability to fully incentivize less-expensive projects and reward them for their ability to deliver credits less expensively. In the early auction periods, the two utility sellers have reported that they have already experienced an oversupply; this also may be because, at the early stages of market development, obligated suppliers may not have been aware of the auction periods and credit availability. Banking rules have allowed the sellers to sell some of the same credits in subsequent auctions. 


\section{Key Structural Elements of ESCs Programs}

Experience with domestic REC markets and ESC markets abroad have helped distill the elements of the required foundation for ESC trading, to be managed by the appropriate PUC or other certifying body. Early examples in Europe have demonstrated that, when administered effectively, ESCs can be an effective complement to existing structures promoting efficiency.

Although this analysis focuses on the compliance side, where there has been more activity, most of the key considerations that must be addressed in a compliance ESC program apply to voluntary markets as well. Many considerations lead to decision points for which there is no clearly demonstrated "correct" policy feature, at least none that has emerged in market development to date. More often, conflicting values must be balanced and solutions are a "work-in-progress." The most fundamental balance of interests is the need to create verification procedures that ensure credibility while controlling transaction costs.

With these caveats in mind, an effective ESC trading platform for EEPS compliance one that instills long-term public and stakeholder confidence - will depend largely on the following key considerations or features (Hamrin et al. 2007):

- Real, measurable, verified savings that take into account the following issues:

o credible certifying body

$\circ$ additionality test that ensures measure is beyond business as usual (BAU)

- rigorous measurement and verification $(\mathrm{M} \& \mathrm{~V})$ based on established protocols

O length of period for which ESCs are issued and up-front ESC issuance where appropriate

- alternative compliance payments

- close scrutiny of double-counting through an established system of tracking and/or certificate/credit attestation process.

○ careful handling of free-rider issue

$\circ$ rules for banking

- Streamlined ownership reporting and tracking system to hold down costs

- Provisions for third-party trading, opening the market beyond obligated entities

- Long-term integration with REC and carbon emission reduction markets where feasible and sensible

- Transparency in rules and transactional information

- Early planning for inter-market, interregional, and international trading

- Providing for ESC ownership in a manner that is fair to both facilities investing in energy savings and organizations providing energy saving services. For example, the installer of high efficiency equipment could give a discount to end users paying for the installation, in exchange for ESC ownership (Bertoldi 2008).

Although values underlying their respective rules are generally shared among the existing ESC trading programs, rules for many of these aspects differ among the countries with 
established ESC trading. This analysis addresses each of these features individually in terms of their treatment within those international energy efficiency obligation schemes where trading of ESCs has occurred - Italy, the UK, France, and New South Wales, Australia.

In addition, the European Commission (EC) has stated an intention to implement ESCs at the European level. The Association of Issuing Bodies, whose mission is to harmonize international energy certificate schemes, has expanded its focus from green certificates (RECs) to also include ESCs. ${ }^{24}$ The EC and other stakeholders are considering a possible mandatory international scheme that would include ESC trading (Bertoldi 2008). They are carefully weighing the equities of such a continent-wide, or even global, trading scheme, most notably how to handle the difficult situation of parties in one country financing projects in another country and the potential such a situation has for weakening national policies or creating unfair burdens or benefits. This is analogous to the issues from one U.S. state to another that would be inherent in a U.S. federal policy. Also, an international ESC compliance market would have to dovetail with existing European carbon markets.

The British scheme, in particular, is a case study in policy features that tend to reduce market size for ESCs. Only a handful of trades have occurred in the British scheme - less than 10 trades combined during the three compliance years of the market (Mundaca et al. 2008). A number of factors cause the low volumes. These include an excess in the available supply of savings (driven also by a high cost-effective potential in the insulation segment and certainty about the penalty in case of noncompliance), a limited number of eligible parties, and perceived transaction costs (related to contract negotiation and liability risks). The banking option in the UK also resulted in fewer trades, as parties have increased their own activity level to use savings for future commitment periods. Lastly, the number of eligible parties has been restricted because only obligated parties are allowed to trade, reducing liquidity. This is crucial because large differences in saving costs among parties are also necessary to trigger trading. Obligated parties also thought that trading activity could involve high negotiation costs, as strategically sensitive information could be disclosed to a buyer/seller. Each of these factors is an object lesson for U.S. policy designers.

\section{Eligible Project Types}

EEPS programs differ significantly in how broad they define project eligibility, and they are not always consistent. In some cases, ESCs may be derived from projects that save energy by making use of thermal waste or another byproduct, such as combined heat and power (CHP). Certain project types, such as solar hot water systems and geothermal heat pumps, may be treated as renewable energy by one program and as efficiency in another.

One of the concerns that has been expressed about the Connecticut program is that there is such an abundance of CHP, in terms of MWh generated, that its inclusion as an eligible resource may make EEPS obligations deceptively easy to meet. The Connecticut program is still too new to make an accurate assessment of this anticipated issue, but the criticism

\footnotetext{
${ }^{24}$ See http://www.aib-net.org/portal/page/portal/AIB_HOME.
} 
underscores the importance of designing a policy for which project eligibility is determined in close conjunction with target stringency. The UK also grants ESCs for CHP projects.

There are many different technology types from which ESCs may be derived, but they are generally no different than projects eligible for an EEPS, from which there are no derived certificates. The exception is that some compliance programs limit the types of eligible projects to keep measurement and verification more streamlined. The other significant distinction among EEPS programs generally is that they don't all include gas efficiency measures.

Projects generally exist within three general overlapping categories: upgrades and retrofits, heating or cooling measures, and load management. ESCs derived from energy savings through reduced electricity consumption may be derived from many different project types. All of the programs grant ESCs for energy-efficient lighting; equipment and appliance upgrades and retrofits, such as those for boilers, motors, and air conditioners; and insulation or other heating or cooling measures, such as HVAC system upgrades, ground source heat pumps, or solar water heating. Some measures also may qualify as renewable energy projects, depending on how they are categorized (Hamrin et al. 2007).

The five programs that feature active trading expand somewhat from this basic list, but none more than Italy in terms of project diversity. In some cases, EEPS and ESC regimes also may include demand-response or load-management measures that shift electricity load from peak to off-peak hours. Eligible project types and practices are listed in Table 6. These could include smart metering, sensors to anticipate heating or cooling, or remote monitoring and control of various energy-intensive applications. 
Table 6. ESC Schemes and Eligible Project Types

\begin{tabular}{|c|c|c|}
\hline $\begin{array}{l}\text { ESC Program, Year } \\
\text { Effective }\end{array}$ & $\begin{array}{l}\text { Eligible Technology Types and } \\
\text { Practices }\end{array}$ & Major Stipulations \\
\hline Connecticut, 2007 & $\begin{array}{ll} & \text { CHP plants } \\
- & \text { Demand response } \\
\text { - } & \text { Load management }\end{array}$ & $\begin{array}{l}\text { Electricity suppliers must } \\
\text { meet a percentage of their } \\
\text { total supply in energy } \\
\text { efficiency and } \mathrm{CHP}^{25}\end{array}$ \\
\hline France, 2006 & $\begin{array}{ll}\text { - } & \text { Double glazing of windows } \\
\text { - } & \text { Heating controls } \\
\text { - } & \text { Insulation } \\
\text { - } & \text { Lighting } \\
\text { - } & \text { Variable speed motors } \\
\text { - } & \text { Wood-firing heating systems }\end{array}$ & $\begin{array}{l}\text { Favors standardized } \\
\text { measures with set energy } \\
\text { savings; customized or less- } \\
\text { common projects are } \\
\text { assessed case-by-case. }\end{array}$ \\
\hline Italy, 2005 & $\begin{array}{ll}\text { - } & \text { Bio-climatic architecture } \\
\text { - } & \text { Control of radiation entering through } \\
\text { - } & \text { Electricity in thermal uses } \\
\text { - } & \text { Heating/cooling and heat recovery } \\
\text { - } & \text { } \text { On-sith nonrenewable energy } \\
\text { - } & \text { Passive cooling } \\
\text { - } & \text { Promotion of electric and natural gas } \\
\text { - } & \text { vehicles } \\
\text { - } & \text { Reduction of air-conditioning } \\
\text { - } & \text { Reduction of passive-draw power } \\
\text { - } & \text { Substitution of electricity to other } \\
& \text { sources }\end{array}$ & $\begin{array}{l}\text { - Half of the goal set for each } \\
\text { year must be obtained by } \\
\text { reductions in the } \\
\text { consumption of electricity } \\
\text { and gas by end-users }\end{array}$ \\
\hline $\begin{array}{l}\text { New South Wales, } \\
\text { Australia, } 2003\end{array}$ & $\begin{array}{ll}\text { - } & \text { Demand-side abatement } \\
\text { - } & \text { Energy efficiency projects reduce or } \\
& \text { replace energy consuming equipment } \\
\text { or processes } \\
\text { - } \quad \text { Forest sequestration of carbon } \\
\text { - } \quad \text { Fuel switching with reduced GHG } \\
\text { emissions } \\
\text { - } \quad \text { New energy efficient equipment } \\
\text { On-site electricity generation with } \\
\text { reduced GHG emissions } \\
\text { Reduction of GHG emissions by } \\
\text { non-electricity sector industries } \\
\end{array}$ & $\begin{array}{l}\text { - Required "benchmark } \\
\text { participants" (i.e., major } \\
\text { electricity producers) must } \\
\text { meet a percentage of the } \\
\text { total benchmark GHG } \\
\text { emissions reductions relative } \\
\text { to their contribution to the } \\
\text { grid. }\end{array}$ \\
\hline United Kingdom, 2002 & $\begin{array}{ll}\text { - } & \text { CHP plants } \\
- & \text { Fuel-switching programs } \\
- & \text { High efficiency hot water tanks } \\
\text { - } & \text { Window glazing }\end{array}$ & $\begin{array}{l}\text { - Half of the savings generated } \\
\text { for compliance must be } \\
\text { derived from low- or } \\
\text { moderate-income family } \\
\text { home }\end{array}$ \\
\hline
\end{tabular}

\footnotetext{
${ }^{25}$ See also Hamrin et al. 2007.
} 
Italy grants ESCs for the broadest of project types within three general categories: electricity, natural gas, or fuel switching combined with energy efficiency (Hamrin et al. 2007). In Italy, at least half of the target set for each year has to be achieved via a reduction of electricity and gas end uses (known as the " $50 \%$ constraint"); the rest can be achieved via primary energy savings in other sectors (Bertoldi et al. 2005).

The other ESC programs grant ESCs for a somewhat smaller range of project types compared to Italy (Hamrin et al. 2007). Besides the standard project types, the UK also grants ESCs for high efficiency hot water tanks, window glazing, and for fuel-switching programs. Both the UK and Connecticut issue ESCs for CHP plants. France issues ESCs for wood-fired heating systems, in addition to the standard list. Some regimes exclude or develop requirements around entire classes of projects. For example, in the United Kingdom, at least half of the savings generated for compliance must be derived from low- or moderate-income family homes. In France, standardized measures with stipulated energy savings are generally favored, whereas customized or less-common projects are assessed on a case-by-case basis. Eligible technologies in France include lighting, insulation, double glazing of windows, heating controls, variable speed motors, and wood-fired heating systems (Hamrin et al. 2007).

Ultimately, behavioral changes also could be included in qualifying project types. In an age of sophisticated Web-based remote-monitoring equipment, rewarding the installation of such equipment through ESC incentives makes sense. For example, ESCs could be created when users switch off energy-intensive equipment during peak time-of-use periods, decrease or increase the set temperature point of their heating or cooling systems, or decrease the size of their equipment (Bertoldi and Huld 2006).

\section{Targets}

For the five active EEPS schemes - Connecticut and the four nondomestic programs - a fundamental question with respect to ESCs is whether the target is stringent enough to necessitate trading. If targets are easily achieved, introducing trading may offer little or no benefit (Loper et al. 2008). Alternatively, the introduction of trading may enable targets to be increased over time. Because the programs considered here are still relatively new, it will take at least a few more years before definitive conclusions can be drawn as to the effect on overall energy savings that trading can provide.

However, the ESC trading program in Connecticut does provide an early indication of the significance of ESC trading. As of mid-2008, the Connecticut C\&LM fund was approximately $\$ 70$ million, while the total value of the ESCs auctioned from the fund in 2008 was estimated at about $\$ 3.3$ million, or a little less than $5 \%$ of the total fund. Therefore, revenues from ESC trading likely will be sufficient to stimulate a reasonable fraction of new projects. Further conclusions about the efficacy of the ESCs in Connecticut are too difficult to draw at this early stage, approximately 18 months into compliance. It is, for example, too difficult to say whether ESCs will make a significant difference in the ability of obligated suppliers to comply with the Connecticut EEPS, should they reach a point where the target levels are challenging to reach. 
EEPS targets are usually (but not always) expressed as a percentage of retail electricity sales. The Italian targets are expressed in terms of energy intensity, defined as energy use relative to gross domestic product, with a goal to reach reductions of $2 \%$ in energy intensity per year until 2015 and $2.5 \%$ each year after until 2030. Gas and electric distribution companies with more than 100,000 retail customers have energy savings targets that ramp up over the five-year period of 2005-09 to a potential total of an estimated 14 terrawatt hours (TWh) for electricity and 3.3 billion cubic meters for natural gas, for a total of about 5.8 million tons of oil equivalent (Mtoe) (Hamrin et al. 2007). In the first year of ESC trading (2006), trading exceeded the annual target of about $86 \mathrm{GWh}$; thus, the target was easily met. France has the unusual rule of no annual compliance requirement; its three-year compliance period of July 2006-09 has only one deadline, at the end of that three-year period. In virtually all regimes, the extent of a given party's obligation depends on that party's share of retail energy sales. The other national targets may be found in Table 7 .

Table 7. Targets for European and Australian Trading Schemes

\begin{tabular}{|l|l|l|l|}
\hline & $\begin{array}{l}\text { Total Target for } \\
\text { Period Duration }\end{array}$ & $\%$ of Annual Demand & Period \\
\hline Italy & 230 petajoules & $0.5 \%$ & $2005-09$ \\
\hline France & 194 petajoules & $1.0 \%$ & $2006-08$ \\
\hline United Kingdom & 468 petajoules & $1.0 \%$ & $2005-08$ \\
\hline New South Wales & $\begin{array}{l}5 \% \text { reduction in per } \\
\text { capital GHG } \\
\text { emissions }\end{array}$ & N/A & $2003-20$ \\
\hline
\end{tabular}

Source: (Hamrin et al. 2007)

Note: One petajoule is equivalent to $100,000 \mathrm{MWh}$.

\section{Certifying Body}

Given the innovative nature of ESCs, it is critical to the long-term health of the markets that a credible, established organization certifies ESCs. This is necessary for both compliance and voluntary markets to function effectively. To ensure the credibility of ESCs, it is important to have an independent entity that establishes the M\&V methodologies and qualifications for parties conducting the $\mathrm{M} \& \mathrm{~V}$, and ensures that the procedures were followed and that the ESC conforms to the established trading rules. Generally, national trading programs employ governmental, quasi-governmental, or established nonprofits to certify that ESCs are what they purport to be. For example, in Italy, the Regulatory Authority for Electricity and Gas certifies the ESCs.

In the United Kingdom, where the Energy Efficiency Commitment (EEC) policy was established in 2001 and runs in three-year cycles from 2002-11, the program is administered by the federal government's Office of Gas and Electric Markets, which periodically audits suppliers' savings claims through sampling and other methods. The compliance rules, however, were developed separately by the Department for Environment, Food, and Rural Affairs. Although suppliers often contract with third parties in the United Kingdom to implement savings projects, they cannot trade ESCs with third parties. Suppliers are allowed to trade among themselves, but only with advance written agreement from regulators. In France, the Ministry of Industry issues 
certificates and administers the program. The French Agency for Environment and Energy Management and other industry groups define acceptable project types. In Connecticut, the public utility commission acts as the certifier, although the M\&V protocols were established by the existing C\&LM fund (the public benefits fund).

\section{Additionality, Free Ridership, and Cream Skimming}

All of the ESC programs seek to require some "additionality" threshold, i.e., a requirement that the projects only qualify if they go beyond what would have happened absent the ESC program, usually referred to as beyond "business as usual" (BAU). Additionality standards address free ridership, seeking enough rigor in excluding free riders or accounting for their presence, to bring credibility to the program. At the same time, regimes also may seek to serve the competing value of rewarding early action. For example, in Italy (where compliance targets took effect in 2005), projects developed in the preceding four-year period are still considered "additional" under their definition and therefore eligible for compliance in subsequent years to reward the early action. Interestingly, the French definition of additionality depends on whether the entity implementing the savings measure is obligated under the compliance target. As long as the technology type is eligible, any project implemented by an obligated party is considered additional, presumably as an incentive for obligated parties to implement their own measures. Non-obligated parties only meet the additionality threshold if the measure is not related to the entity's main activity - that is, energy efficiency companies and ESCOs are precluded.

\section{Trading Rules: Obligated Entities and Parties Eligible to Trade}

For ESC implementation, a key issue is determining which parties are obligated under compliance regimes, as well as which parties should be eligible to participate in trading. Theoretically, the more parties eligible to participate, the more likely it is to increase the base of efficiency projects and decrease prices. However, involving a larger number of parities adds some administrative complexity and can pose challenges for ensuring that $\mathrm{M} \& \mathrm{~V}$ protocols are followed. Widening participation also might increase the chances of introducing nonadditional efficiency projects, other than those that might have occurred otherwise (Loper et al. 2008).

The Italian program, effective in January 2005, requires compliance from gas and electric distribution companies that had more than 100,000 customers in 2001. The rules in Italy allow energy service companies (ESCOs) to earn credits and sell them to the distribution companies, which can use the acquired ESCs (in conjunction with those from their own efficiency measures) to meet their EEPS obligations (Hamrin et al. 2007). The distribution utilities also are allowed to trade with one another and are also allowed to operate efficiency programs in partnership with ESCOs. Italy has an open policy on participation in the energy savings compliance market. Market sessions are held regularly and parties may sell only ESCs that are registered in their account in the ESC registry overseen by the Regulatory Authority.

In contrast to Italy, in France, the UK, and Connecticut, retail suppliers and not distribution companies are obligated (Bertoldi 2008). Determining which parties should 
be obligated is partly an issue of cost recovery: normally, distribution companies and their tariffs are regulated. For them, a wires charge can be used to pay the costs they incur to implement ESCs up to their saving target (either a fixed-cost recovery as in Italy or based on the cost of the ESC). Retailers are usually outside the regulated tariffs, so are free to charge their customers for the energy efficiency projects (Bertoldi 2008).

In the UK, where retail electricity markets are deregulated, suppliers sometimes contract with third parties to deliver energy savings, and must report their savings quarterly to the Office of Gas and Electric Markets, which verifies the savings. In the UK, only suppliers with at least 50,000 customers are obligated; this limits the effect of the obligation on new entrants to the market (Bertolodi et al. 2005).

In France, the obligated parties include electricity, natural gas, domestic fuel, and heating and cooling suppliers, but not smaller suppliers of less than $400 \mathrm{GWh}$ per year in energy sales (Hamrin et al. 2007). Companies whose core business is energy efficiency are not permitted to trade, because the rules are structured to define their implemented measures as "nonadditional" because they are in the business of implementing such measures.

\section{Measurement and Verification}

Each ESC trading program develops its own protocols for M\&V. They often use established templates, such as the International Performance Measurement and Verification Protocol, as a guide. Focused on commercial and industrial applications, the IPMVP covers a broad range of measures, including fuel savings, water efficiency, load shifting, and equipment upgrades. Others rely on existing protocols that already have been developed for public benefits funds that support efficiency measures. At this very early stage, with only a few ESC markets established, it will be useful for policy makers to use such guides and existing protocols. Consistency among trading regimes as they form will ease and, in some cases, even make possible interregional and international ESC trading. This could become crucial in later stages of market development, especially if ESCs become part of global GHG markets.

$\mathrm{M} \& \mathrm{~V}$ can be one of the most complex and expensive elements of ESC trading. As REC markets have amply demonstrated, public scrutiny of the credibility, integrity, and transparency of markets that allow trading can be greater than compliance regimes that do not. In addition to the methods for individual project measurement and verification, ESC programs also generally require licensed engineering contractors to conduct the work or independently verify the savings. In addition, for the integrity of a trading program, projects should generate ESCs only for the period they are actually generating the savings, which varies depending on project type and other variables. Measured lifetimes are generally stipulated for classes of measures, based on previously conducted measure retention studies.

Because ESC trading can carry additional costs to an EEPS compliance program, it is particularly important for policy makers considering the implementation of ESC trading to find streamlined, cost-saving approaches. These include $\mathrm{M} \& \mathrm{~V}$ methods that are 
practical yet established ways to acquire accurate estimated savings data at lower-cost points: computer-based simulation and deemed savings.

The most accurate methods for determining savings involve measuring end-use consumption and then imputing savings based on a projection of baseline energy use, or conducting whole building measurement. End-use measurement can be conducted on either a project-specific basis or for samples of similar projects. In the former case, measurements are made by installing data loggers on project submeters or circuitry to measure consumption, or using other field measurement methods to make accurate assessments of savings associated with the specific measure. These are generally also the most expensive and are not always feasible at any cost. An example of field measurement is isolating energy retrofits from the rest of a building to gauge the savings attributable to the retrofit. End-use M\&V can entail different levels of accuracy and expense, depending on what parameters are monitored instead of spot-measured, the accuracy of the instrumentation, and the duration of the monitoring period.

But because of the expense involved, gathering actual end-use consumption data is practical only for the largest savings measures, where key parameters such as how many hours a large HVAC system is used can change results markedly. Measurement options that incorporate both actual and stipulated data, such as partially measured retrofit isolation, involve field measurement of savings combined with certain stipulated parameters and can present hybrid compromise between the accuracy of actual data and the savings in estimating data (Bertoldi and Huld 2004). Another method for measuring savings is known as the whole-buildings approach, for which the collective savings of a series of measures within a structure are inferred from the energy savings from one or more measures, based on the change in energy use at the building level or on utility billing data.

Computer-based simulation determines savings through software designed to predict energy use and demand patterns that match actual use (Bertoldi and Huld 2006). Deemed savings methods use historical or so called "ex-ante" data (predetermined from previous similar projects or established engineering methods), to make assumptions about the savings a given project will create. They may incorporate assumptions or default factors for free ridership and for the persistence of energy savings, or how long they will last (Vine and Hamrin 2008). The method works particularly well for established technologies for which data tends to be more reliable, such as lighting measures. The deemed savings method is being used by NYSERDA in their pilot program and is relied on heavily in the Italian program as well.

Italy also has used preliminary engineering calculations to preapprove projects with more innovative technologies for which historical data is not available (Hamrin et al. 2007). For savings to be additional under the Italian definition, they must exceed market trends and legislative requirements (Hamrin et al. 2007). Italy uses engineering estimates and "standard savings factors" for natural gas decompression, certain variable speed drives, $\mathrm{CHP}$, and district heating. For other projects in the Italian program, energy monitoring 
methods are used to take a "before and after" energy picture, after which variables such as weather and occupancy levels are factored in.

In the United Kingdom, deemed savings (based on previous measurements and engineering methodologies) is the predominant M\&V approach. Preapproved savings estimates are also weighted for fuel type and discounted using a discount factor of 3.5\% over the lifetime of the measure. For projects relying on government funding, savings are further discounted, as a policy preference to maximize private funding. For several project types, savings may be based on monitoring of a valid project sample. The demonstration of additionality is also a function of project type. Deemed savings in France are based on "fast and straightforward user-friendly procedures" stemming from sampling or engineering calculations (Hamrin et al. 2007).

Deemed savings can be particularly useful where ESC programs have access to historical data from efficiency measures implemented within a systems benefit program over the course of several years. Sampling involves using measured savings from a statistically valid sample of similar projects to draw conclusions about other similar projects, rather than evaluating each project separately. Connecticut has a detailed "Technical Reference Manual" with deemed savings values, engineering methodologies, and related data for all of the allowable technology types eligible for Class III certificates, more than 50 in the approximately 250-page document. Similarly, the UK uses a "Technical Guidance Manual" for deemed savings for established technology types.

Because of the many variables involved in measuring savings, some have suggested that the certificates represent savings over several years, rather than a single year, the approach taken by NYSERDA. The advantage is that the longer time period can result in "smoothing out" variations such as those caused by weather (Bertoldi and Huld 2004). In addition, it can be easier to administer, because ESCs can be issued up front for the lifetime of the savings, meaning that certification only needs to occur once. However, if this approach is taken, some form of discounting the savings also may be appropriate to account for any risk that actual savings do not occur.

ESC M\&V protocols have the double challenge of establishing accurate baselines, or reference scenarios - the "before" picture for an energy savings measure and its forecasted energy use absent the savings measure to determine savings. The baseline is important to establish that the measure resulted in savings beyond business as usual. Different M\&V methodologies have their own guidelines for establishing baselines. For example, a deemed savings approach imputes baselines, eliminating the need to project baseline energy use. For commercial and industrial retrofits, baselines are informed by the equipment installed at the customer's site before the retrofit. ${ }^{26}$

\section{Reporting and Tracking Requirements}

Generally, the ability to use an automated Web-based ESC tracking program is important for controlling ESC program administrative costs. Such tracking systems streamline

\footnotetext{
${ }^{26}$ If the original equipment was below minimum efficiency standards, the baseline will often be set at the standard level to avoid paying someone just to come up to code.
} 
registration, chain of custody, and can minimize the risk of double-counting. The use of an automated system can ensure each ESC is identified by a unique serial number that need not be identified manually. Automated, Web-based tracking systems can help the certification process by efficiently generating the necessary reports for certifying bodies.

The parameters and requirements for ESC-tracking software already exist and need only be licensed by governments or other bodies for further development specific to their needs. In spring 2008, APX established the North American Renewables Registry, which is specifically designed partly to track ESC ownership and deal with issues such as M\&V that are specific to ESCs. In some cases, similar to that of Connecticut, an existing REC registry (the NEPOOL GIS system) with similar functionality to that required by ESC markets can be used. In Italy, the Regulatory Authority runs a separate ESC registry and charges annual and transaction fees (Hamrin et al. 2007).

In Italy, the certifying body, such as the PUC or other regulating body, normally oversees the method of tracking and verifying ESC ownership. Ideally, however, there is independent oversight, so that regulating and rule-making as well as the processes of issuing, tracking, and certifying ESCs are not all in the hands of the same organization.

In Italy, there is a separate market operator that issues and registers ESCs at the request and oversight of the certifying body, the Regulatory Authority for Electricity and Gas (Hamrin et al. 2007). But the two organizations are independent of one another. In Connecticut, the DPUC reviews an annual blanket plan (incorporating an M\&V plan) submitted by each of the two utilities administering the C\&LM fund. Other independent energy savings companies and energy savings project implementers in Connecticut must apply separately, on a project-specific basis, with the DPUC for Class III issuance, and submit independently verified M\&V plans for the project before certificates will be issued. Once issued, the company can apply to the NEPOOL GIS for the requisite number of certificates to be deposited into their GIS account, at which point wholesalers seek buyers and, once found and a transaction completed, certificates can be transferred to the buyer's account, which can then be used to demonstrate compliance to the DPUC.

Collecting, verifying, and entering $\mathrm{M} \& \mathrm{~V}$ project data into a tracking system can be costly, especially if data must be entered into a system manually. Each project might have a different verifier for its savings data, which can be similarly difficult to manage. Unlike RECs, which benefit from metered data verified through an ISO, there is no automated system for capturing savings data

As markets develop, it is important that tracking systems are developed to be as compatible with one another as feasible, so that eventually trades between accountholders of different systems can be completed. The lack of central planning in this respect for RECs has created some extra back-end difficulties five or more years into the development of REC tracking systems, because interregional trades were not fully accommodated. As a result, REC tracking systems have incompatibilities. 


\section{Length of Issuance Period, Up-front Issuance, and Banking Rules}

ESC programs anticipate incremental increases in savings that incorporate gains from the previous years. ESCs from a given project can be either reissued annually for a fixed number of years, which is the norm, or issued the entire lifetime's worth of ESCs up front. The length of the lifetime may be based on a "one-size-fits-all" approach to projects, such as a five- or 10-year maximum lifetime. Alternatively, lifetimes may be defined for individual technology types, reflecting the actual length of time during which savings can reasonably be expected for that type, based on the history of the project type and other variables.

In determining the number of years for which a given project should be issued ESCs, policy makers often adopt a simplified approach with a predetermined number of years applied to all projects, regardless of the reality of how long the project would actually yield savings. This is a policy decision that again favors the value of simplicity and ease in planning, meant to reduce the administrative difficulty of implementation, instead of attempting to ascertain more specific, accurate savings measures.

Some ESC plans, such as the voluntary program being developed by NYSERDA, grant the full complement of ESCs up front for the full value of the expected savings over the life of a project. This approach simplifies administration and maximizes the financial leverage ESCs can provide in shortening a project's payback period as well as the chances of the project receiving the initial green light through up-front financing. But as a trade-off for accessing the full value up front and because of the time value of ESCs and the proceeds they can bring, such up-front issuances are normally discounted to some degree. On the other end of the spectrum is the granting of ESCs annually over the life of the project, as is the case in Italy, which does not incorporate future savings into ESC issuance.

There also are significant differences in the number of years for which ESCs are granted. Italy grants ESCs for five years for most projects, but allows eight years worth of ESCs for certain projects, including passive cooling, thermal building insulation, and solar water heating, expected to generate savings for a longer average period of time. The normal Italian project lifetime of five years carries an implied obligation to maintain the measure for five years (Hamrin et al. 2007).

In the United Kingdom, to minimize transaction costs, an up-front discounted savings is given to a project (based on its expected lifetime), which is used for the three-year compliance cycle in which the measure is implemented - this is similar to the NYSERDA approach. ${ }^{27}$ But the UK credits projects with long lifetime projected savings for the full lifetime of savings, even if it is 20 years, to provide ample incentives for such projects.

The annual reissuing of ESCs for a given project, based on the additional savings the project is generating each year, should not be confused with the ability of ESC holders to bank ESCs for a period of time. "Banking" refers only to the timing of the sale of an

\footnotetext{
${ }^{27}$ Because of the cost of capital and other factors, there is normally a discount factor applied when ESCs are issued up-front for their lifetime's worth of savings.
} 
ESC. For example, a seller unable to find the desired sale price or counterparty for a given sale or auction period may simply hold the ESC for a future sale, as allowed by the banking rules. For the five-year compliance period in Italy, the projects given five years worth of ESCs are also allowed unlimited banking; in other words, once issued, ESCs can be used in any compliance year within the five-year period. The new Michigan EEPS provides that ESCs created in one year may be carried forward to the next, but only to a maximum of one-third of that next year's standard. ${ }^{28}$

\section{Alternative Compliance Payments (ACPs)}

EEPS policies in the United States do not generally include an "alternative compliance payment" (ACP); on the other hand, many U.S. state RPS policies do. An ACP is an amount of money required for each MWh an obligated party falls short of their requirement of renewable energy or energy efficiency. ACPs can also be used as a mechanism for supporting new efficiency projects by placing ACP dollars into an efficiency fund, for funding projects. For those states considering the use of ESCs, an ACP can help obligated parties to clarify the cost of noncompliance and, consequently, the value of projects that comply with the EEPS. Some states, such as California, have shareholder incentive structures, which reward utilities for exceeding their target, and in some cases, penalize them for falling short. Sanctions or penalties generally are an important part of compliance; it is necessary to make penalties large enough to incentivize requirements and ensure compliance.

In Connecticut and in Europe, plan designers seek to set an ACP at a high enough level to ensure appropriate incentives for compliance. The first step in setting an ACP is an accurate assessment of the averages and ranges in the per-MWh cost of installed efficiency measures. It is one of the more difficult parameters to determine, because costs and values for energy efficiency measures vary greatly. In the end, ACPs need to be set at a level cost level few projects would exceed, to ensure that the proper incentive to pursue even high payback projects is in place. Too low an ACP could discourage project development. Connecticut, the only state with active ESC trading, has set both an ESC price floor $(\$ 10 / \mathrm{MWh})$ and a ceiling in the form of an ACP $(\$ 31 / \mathrm{MWh})$.

In Italy, the Regulatory Authority for Electricity and Gas (AEEG) assesses compliance with targets and sets the price for noncompliance on a case-by-case basis (Pavan 2008). As a guideline, the ACP must be equal to or higher than the trading price. Interestingly, the Italian regulators do not define the value of the penalty in advance; it isn't a reference price. The reason for this approach is to prevent the market from sending false signals about the real cost of energy saving. Rather, the policy objective is to allow maximum market responsiveness to the "moving target" market value of energy efficiency. Generally, AEEG looks at the average market price of certificates and the average cost of saving energy and sets an appropriate price. The revenue from the ACP in Italy goes toward educational programs about energy efficiency.

\footnotetext{
${ }^{28}$ See Michigan Enrolled Senate Bill No. 213, Section 83 (3) (a).
} 


\section{Conclusions}

Early experiences with ESCs have demonstrated that they are worth careful consideration, especially in the context of EEPS compliance. In the United States, the ESCs may benefit from the confluence of several emerging factors: new state EEPS policies, public interest in tools to mitigate climate change, and the beginnings of interest in a voluntary market for ESCs.

Voluntary markets can benefit from lessons learned in compliance markets, particularly with regard to $M \& V$ protocols and certification processes. The results from early pilot programs, such as NYSERDA's, will be important to those considering emulating such programs. But for the voluntary market, the emergence of a credible, independent national certifying body and consistent set of protocols is paramount. Similarly, the success of early examples of the use of ESCs for EEPS compliance, such as the program in Connecticut, also will be watched closely by stakeholders. The staying power of European examples, particularly in Italy, already demonstrates that ESCs can bring added revenue and attention to energy efficiency. The European examples to date also indicate significantly higher prices for ESCs than the data available in the United States would indicate for the very limited U.S. market to date.

Not entirely different from the early experience of REC markets, public and policy-maker perceptions of the ability to accurately capture and measure energy savings vary, and attempting to do so in the context of tradable certificates is still a new concept. ESCs will not be helped by a perception that measurement and verification is inconsistent or unreliable. For this reason, it is particularly important to the market's future that a single, independent national certifying body promotes consistent practices that encompass both voluntary and compliance markets. Lessons from compliance markets also will be crucial for an emerging national voluntary market.

The development of robust markets for ESCs will depend on consistency and clarity in standards and protocols as well as the ability of the industry to speak with a central voice. Ensuring that savings are real, verifiable, and additional is necessary for the market to gain credibility. Proper handling of the issue of free ridership is particularly important to preserve market integrity, especially on the voluntary side of the market, which depends so heavily on public perception.

REC markets have shown that there may be potential to broaden and integrate markets for tradable commodities that represent a public good and an opportunity for consumers to "vote with their wallets." ESCs can benefit from the traction that RECs have gained in the marketplace, along with the existing infrastructure developed for REC markets, such as tracking systems. These systems could be relatively easily modified to accommodate ESC trading. ESCs can also benefit from existing M\&V protocols and other data acquired through long-standing efficiency and public benefit programs. But with a somewhat different value proposition, it is unclear whether ESCs will mirror RECs market progress. 
Making use of these existing structures is crucial for ESC regimes to succeed, given that transaction costs are perhaps the single greatest market hurdle for ESCs to overcome.

Keeping administrative, certification, and tracking costs low will enable market traction, given the relatively low profit margins to be expected with the product. Large programs that involve more parties also can help to diffuse these costs and help ensure adequate $\mathrm{M} \& \mathrm{~V}$ oversight. The importance of leveraging existing $\mathrm{M} \& \mathrm{~V}$ data and structures is amply demonstrated in both the Connecticut and NYSERDA examples, where ESC programs benefit from $M \& V$ protocols enacted by public benefit funds developed over a long period of time to implement energy efficiency measures. As these very new programs develop, other states can draw from these programs' experiences in attempting to replicate their successes.

There are strong motivating influences at work to promote a variety of mechanisms that support increased energy savings. Although the timing may be good for ESCs to move toward greater public and policy-maker acceptance and eventually toward some critical mass, ESCs also face obstacles to that acceptance that go beyond those of RECs. For the voluntary market that has played a key role in REC development, ESCs have an essentially challenging value proposition: selling the environmental benefits of a measure that has already bestowed a personal benefit of savings on the seller. It is too soon to know whether the benefits of ESCs will ultimately outweigh those challenges. As the general public and policy makers continue to warm to the idea of requirements that build in market-based flexibility, such as REC and carbon offset trading, the potential exists for ESCs to play a role in expanding markets for energy efficiency. 


\section{References}

American Council for an Energy-Efficient Economy (ACEEE). (2008). Role of Energy Efficiency in Climate Policy. Washington, D.C. American Council for an EnergyEfficient Economy, www.aceee.org, May 2008.

Bird, L.; E. Holt; and G. Carroll. (2007). "Implications of Carbon Regulation for Green Power Markets," NREL/TP-640-41076. Golden, CO: National Renewable Energy Laboratory, April. http://www.eere.energy.gov/greenpower/resources/pdfs/41076.pdf

Bird, L. and Swezey, B. (2004). "Green Power Marketing in the United States: A Status Report (Seventh Edition)," NREL/TP-620-36833, October 2004.

Bertoldi, P. and T. Huld. (2006) "Tradable certificates for renewable energy and energy savings." Energy Policy. 34: pp. 212-222.

Bertoldi, P.; S. Rezessy; and D. Urge-Vorsatz. (2005a). "Tradable Certificates for Energy Savings: Opportunities, Challenges, and Prospects for Integration with Other Market Instruments in the Energy Sector," Energy and Environment, 16(6): 959-992.

Bertoldi, P.; Langniss, O.; Rezessy, S.; Voogt, M. (2005b). "White, Green \& Brown Certificates: How To Make The Most Of Them?" ECEEE 2005 Summer Study - What Works \& Who Delivers?

Capoor, K. and P. Ambrosi. (2008). "State and Trends of the Carbon Market 2008." World Bank. URL: http://carbonfinance.org/docs/State Trends-formatted 06_May_10pm.pdf

Database of State Incentives for Renewable Energy and Energy Efficiency. DSIRE: Rules, Regulations, \& Policies for Energy Efficiency: http://www.dsireusa.org/summarytables/regee.cfm?\&CurrentPageID=7\&EE=1\&RE=1 Accessed July 2008.

Elliott, R.N.; M. Eldridge; A.M. Shipley; J. Laitner; S. Nadel; A. Silverstein; B. Hedman; and M. Sloan. (2007). "Potential for Energy Efficiency, Demand Response, and Onsite Renewable Energy to Meet Texas's Growing Electricity Needs." American Council for an Energy-Efficient Economy, Report Number E073, Washington D.C.

Energy Information Agency (EIA). "Demand-Side Management Program Energy Savings.” Form EIA-861, Electric Power Annual. Table 9.6 Demand-Side Management Program Energy Savings, 1995 through 2006. http://www.eia.doe.gov/cneaf/electricity/epa/epat9p6.html

European Commission. (2005). "Green Paper on Energy Efficiency: Doing More with Less,” Brussels, June 2005. 
Frontier Associates, LLC. (2008). Energy Efficiency Accomplishments of Texas Investor Owned Utilities, Calendar Year 2007. http://www.texasefficiency.com/report.html.

Geller, H. (2006). "Catching up: Progress with utility energy efficiency programs in the Southwest." Proceedings of the 2006 Summer Study on Energy Efficiency in Buildings. Washington, D.C., American Council for an Energy-Efficient Economy.

Hamilton, K.; Sjardin, M.; Marcello, T.; Xu, G. (2008). "State of the Voluntary Carbon Markets 2008." Ecosystem Marketplace and New Carbon Finance. URL:

http://ecosystemmarketplace.com/documents/cms_documents/2008_StateofVoluntaryCar bonMarket.4.pdf

Hamrin, J.; E. Vine.; and A. Sharick. (2007). "The Potential for Energy Savings Certificates as a Major Tool in Greenhouse Gas Reduction Programs.” Prepared by the Center for Resource Solutions for the Henry P. Kendall Foundation, May.

http://www.resource-

solutions.org/lib/librarypdfs/Draft Report ESC V12 cleanFINAL 5-24-07.pdf.

International Performance Measurement \& Verification Protocol. Concepts and Options for Determining Energy and Water Savings, Volume 1. DOE/GO-102002-1554. March 2002. www.ipmvp.org.

Itron, Inc. (2008). “Assistance in Updating the Energy Efficiency Savings Goals for 2012 and Beyond." Consultant report to the California Public Utilities Commission. http://www.cpuc.ca.gov/PUC/energy/electric/Energy+Efficiency

Jacobson, D. and C. High. (2008). "Wind Energy and Air Emission Reduction Benefits: A Primer," subcontract report prepared for the National Renewable Energy Laboratory, Golden, CO, NREL/SR-500-42616, February. http://www.eere.energy.gov/windandhydro/windpoweringamerica/pdfs/policy/wind air emissions.pdf

Koomey, J. (2008). Project scientist, Lawrence Berkeley National Laboratory; and consulting professor, Stanford University. Testimony before the Joint Economic Committee of the United States Congress. For a hearing on Efficiency: The Hidden Secret to Solving Our Energy Crisis.” July 30, 2008. http://jec.senate.gov/index.cfm?FuseAction=Files.View\&FileStore id=bfe4a7d0-6705$\underline{4482-a 75 c-299 b 838153 \mathrm{e} 3}$.

Loper, J.; J. Harris; L. Ungar; S. Capanna; S. Devranolglu. (2008). "Deal or No Deal? Pros and Cons of Trading Under an Energy Efficiency Resource Standard." Alliance to Save Energy, Washington, D.C.

Mundaca, L.; L. Neij; N. Labanca; Bruno Duplessis; Lorenzo Pagliano. (2008). "Market Behaviour And The To-Trade-Or-Not-To-Trade Dilemma In 'Tradable White Certificate' Schemes." 
Pavan, M. (2008). "Not just energy savings: emerging regulatory challenges from the implementation of tradable white certificates." 2008 ACEEE Summer Study on Energy Efficiency in Buildings.

Socolow, R.; Pacala, S.; Greenblatt, J. (2004). “"Wedges’: Early Mitigation With Familiar Technology." Proceedings of GHGT-7, the 7th International Conference on Greenhouse Gas Control Technology, Vancouver, Canada, September 5-9, 2004

Vine, E. (2008). "Breaking Down The Silos: The Integration Of Energy Efficiency, Renewable Energy, Demand Response And Climate Change." 1:49-63 DOI 10.1007/s12053-008-9004-z, February 2008.

Vine, E.; Hamrin, J. (2008). "Energy savings certificates: A market-based tool for reducing greenhouse gas emissions.” Energy Policy. 36: 467-476, October 2007. 


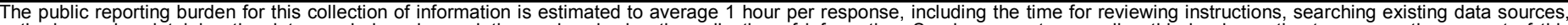

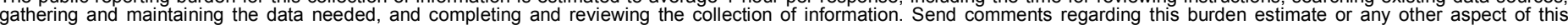

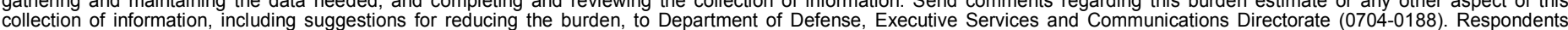

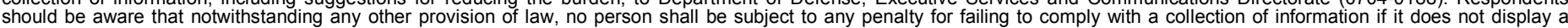

chould be aware that notwithstandin.

PLEASE DO NOT RETURN YOUR FORM TO THE ABOVE ORGANIZATION.

\begin{tabular}{l|l|l|} 
1. REPORT DATE $(D D-M M-Y Y Y Y)$ & 2. REPORT TYPE & 3. DATES COVERED (FrOm - TO)
\end{tabular}

October 2008

Technical Report

4. TITLE AND SUBTITLE

Certificates

5a. CONTRACT NUMBER

DE-AC36-08-G028308

5b. GRANT NUMBER

5c. PROGRAM ELEMENT NUMBER

5d. PROJECT NUMBER

NREL/TP-670-44072

Barry Friedman, Lori Bird, and Galen Barbose 5e. TASK NUMBER

SA07.8730

5f. WORK UNIT NUMBER
7. PERFORMING ORGANIZATION NAME(S) AND ADDRESS(ES)

National Renewable Energy Laboratory

1617 Cole Blvd.

Golden, CO 80401-3393

9. SPONSORING/MONITORING AGENCY NAME(S) AND ADDRESS(ES)
8. PERFORMING ORGANIZATION REPORT NUMBER

NREL/TP-670-44072

10. SPONSOR/MONITOR'S ACRONYM(S) NREL

11. SPONSORING/MONITORING AGENCY REPORT NUMBER

\section{DISTRIBUTION AVAILABILITY STATEMENT}

National Technical Information Service

U.S. Department of Commerce

5285 Port Royal Road

Springfield, VA 22161

13. SUPPLEMENTARY NOTES

14. ABSTRACT (Maximum 200 Words)

Early experiences with energy savings certificates (ESCs) have revealed both their merit and the challenges associated with them. In the United States, there has been little activity to date, so any lessons must be drawn from experiences in Italy, the United Kingdom (UK), France, and elsewhere. The staying power of European examples, particularly in Italy, demonstrates that ESCs can help initiate more efficiency projects. Although a robust market for renewable energy certificates (RECs) has emerged in both the voluntary and policy compliance contexts in the United States, ESCs have yet to gain significant traction. This report looks at the opportunity presented by ESCs, the unique challenges they bring, a comparison with RECs that can inform expectations about ESC market development, and the solutions and best practices early ESC market experience have demonstrated. It also examines whether there are real market barriers that have kept ESCs from being adopted and what structural features are necessary to develop effective trading programs.

15. SUBJECT TERMS

energy savings certificates; ESCs; energy efficiency; renewable energy; renewable energy certificates; RECs; state policy; renewable energy development; state policy makers; renewable portfolio standards; RPS

\begin{tabular}{|c|c|c|c|c|}
\hline 16. SECURITY & CLASSIFICATI & N OF: & 17. LIMITATION & 18. NUMBER \\
\hline $\begin{array}{l}\text { a. REPORT } \\
\text { Unclassified }\end{array}$ & $\begin{array}{l}\text { b. ABSTRACT } \\
\text { Unclassified }\end{array}$ & $\begin{array}{l}\text { c. THIS PAGE } \\
\text { Unclassified }\end{array}$ & $\begin{array}{l}\text { OF ABSTRACT } \\
\text { UL }\end{array}$ & \\
\hline
\end{tabular}

